\title{
Study on the Pressure Drop Variation and Prediction Model of Heavy Oil Gas-Liquid Two-Phase Flow
}

\author{
Shanzhi Shi, ${ }^{1}$ Jie Li, ${ }^{1}$ Xinke Yang, ${ }^{1}$ Congping Liu, ${ }^{1}$ Ruiquan Liao $\mathbb{D}^{2,3}$ Xingkai Zhang, ${ }^{2,3}$ \\ and Jiadong Liao $^{2,3}$ \\ ${ }^{1}$ Research Institute of Engineering Technology of Xinjiang Oilfield Company, Karamay, China \\ ${ }^{2}$ Petroleum Engineering College, Yangtze University, Wuhan, China \\ ${ }^{3}$ The Branch of Key Laboratory of CNPC for Oil and Gas Production, Yangtze University, Wuhan, China
}

Correspondence should be addressed to Ruiquan Liao; 100619@yangtzeu.edu.cn

Received 8 August 2020; Revised 16 October 2020; Accepted 13 April 2021; Published 29 April 2021

Academic Editor: Reza Rezaee

Copyright (c) 2021 Shanzhi Shi et al. This is an open access article distributed under the Creative Commons Attribution License, which permits unrestricted use, distribution, and reproduction in any medium, provided the original work is properly cited.

\begin{abstract}
To explore the pressure drop variation with the viscosity of heavy oil gas-liquid two-phase flow, experiments with different viscosity gas-liquid two-phase flows are carried out. The experimental results show that the total pressure drop increases with increasing liquid viscosity when the superficial gas and liquid flow rates are the same. The liquid superficial velocity is $0.52 \mathrm{~m} / \mathrm{s}$, and the superficial gas velocity is $12 \mathrm{~m} / \mathrm{s}$ in the vertical and inclined pipes, as there is a negative friction pressure drop when the superficial gas and liquid velocities are small. Additionally, the increased range of the total pressure drop decreases with increasing liquid viscosity. Considering the heavy oil gas-liquid two-phase flow, a prediction model of the pressure drop in highviscosity liquid-gas two-phase flow is established. The new model is verified by experimental data and compared with existing models. The new model has the smallest error, basically within $15 \%$. Based on the prediction of the wellbore pressure distribution of four wells in the BeiA oilfield, the new model prediction results are closer to the measured results, and the error is the smallest. The new model can be used to predict pressure drops in high-viscosity gas-liquid two-phase flow.
\end{abstract}

\section{Introduction}

As recoverable reserves of conventional crude oil are decreasing worldwide, heavy oil plays an important role in the energy supply. During heavy oil development, the problem of high-viscosity fluid flowing in the wellbore is apparent. However, high viscosity poses great challenges for the production and transportation of heavy oil. In addition, gas and water are inevitably concurrently present with the oil in the pipeline flow process; thus, gas-liquid two-phase flow behavior is more complex and difficult to predict [1].

However, most liquid holdup and pressure drop models have been developed based on low liquid viscosity $[2,3]$. Scholars have recently carried out theoretical and experimental studies on high-viscosity gas-liquid two-phase flow. Schmidt et al. [4] conducted an experimental study on the phase and velocity distributions of the gas-liquid two-phase flow of a high-viscosity fluid (viscosity up to $7000 \mathrm{mPa} \bullet \mathrm{s}$ ) in a vertical upward pipe. The experimental results show that the existing void fraction model cannot agree with the void fraction data under high-viscosity fluid. Zhang et al. [5] summarized the research progress of high-viscosity oil and compared it with the multiphase flow of low-viscosity oil (including the flow pattern, pressure gradient, and liquid holdup). The experimental results indicate that the flow behaviors of high-viscosity oil and low-viscosity oil are quite different. Jeyachandra et al. [6] studied the effects of high viscosity and pipe diameter on the drift velocity of horizontal and upward inclined pipes by conducting gas-liquid twophase flow experiments and proposed a new high-viscosity drift velocity model suitable for horizontal to vertical pipes. Farsetti et al. [7] studied high-viscosity gas-liquid twophase flow in horizontal and inclined pipes through experiments. The pressure gradient, bubble frequency, and length were the main parameters measured in the experiment. By comparing the prediction results of existing low-viscosity 
models, the existing models showed poor prediction ability for the flow behavior of high-viscosity fluids. Chung et al. [8] studied the effect of high-viscosity oil $(122-560 \mathrm{mPa} \bullet \mathrm{s})$ on oil-gas flow behavior in vertical downward flow, measured the pressure drop and liquid holdup data, and compared the experimental data of gas and water; they found that the viscosity has a significant impact on the flow behavior. Al-Ruhaimani et al. [9] studied high-viscosity oil-gas two-phase flow in a vertical upward pipe and found that the friction pressure gradient of liquid increases with increasing viscosity. In addition, the negative friction pressure drop phenomenon of high-viscosity oil-gas multiphase pipe flow was studied. Akhiyarov et al. [10] studied high-viscosity oilgas two-phase flow in vertical pipes and found that a negative friction pressure drop affected the prediction results. Liu [11] studied vertical gas-liquid two-phase pipe flow. The drop in the liquid film in the Taylor bubble section resulted in a negative friction pressure drop phenomenon, and the possibility of a negative friction pressure drop phenomenon has been proven by analysis of the quantity conservation equation. Al-Sarkhi et al. [12] studied the negative friction pressure drop phenomenon of plug flow in high-viscosity oil-gas two-phase flow in vertical pipes and qualitatively analyzed the causes of the negative friction pressure drop phenomenon from the shear stress.

According to previous studies, most multiphase flow models are developed based on the experimental results of low-viscosity fluids, although the flow behavior of highviscosity fluids is significantly different from that of lowviscosity fluids. When these models are used to predict the flow behavior of high-viscosity fluids, they are quite different from the measured data $[13,14]$. In addition, research on high-viscosity liquid-liquid two-phase flow has recently begun, but due to the limitations of experimental conditions, the development of this research is relatively slow; therefore, there is no comprehensive model to predict the pressure drop under different flow patterns of high-viscosity liquid.

Considering the existing problems, the gas-liquid twophase flow in the wellbore of heavy oil production is taken as the research object in this paper. The change rule of the pressure drop in gas-liquid two-phase flow with the change in liquid viscosity is explored through an indoor physical model experiment. By using the mechanical equation of gas-liquid two-phase flow combined with the appropriate closed relation formula, a prediction model of the pressure drop in high-viscosity liquid-liquid two-phase flow is established, which provides theoretical support for accurately predicting the wellbore pressure distribution of gas-liquid two-phase flows of different viscosities.

\section{Experiment of Gas-Liquid Two-Phase Flow with Different Liquid Viscosities}

\subsection{Experimental Fluid and Equipment}

2.1.1. Experimental Fluid. The gas phase of the gas-liquid two-phase flow experiment with different viscosities is air, and the liquid phase is a tackifying white oil. The viscosity test results of the tackifying white oil are shown in Figure 1.
By fitting the experimental data, the mathematical relationship between the temperature and the viscosity of the tackifying white oil can be determined as follows:

$$
\mu_{1}=-0.0033 T^{3}+0.5599 T^{2}-33.597 T+765.36,
$$

where $\mu_{1}$ is the viscosity of the tackifying white oil, $\mathrm{mPa} \bullet \mathrm{s}$; and $T$ is the temperature, ${ }^{\circ} \mathrm{C}$.

The gas-liquid two-phase flow experiment with different oil viscosities can be carried out by changing the temperature.

2.1.2. Multiphase Flow Experiment Device and Process. This experiment is carried out on a multiphase flow experimental platform. The main process of the experiment is described as follows: the liquid in the mixing tank is pressurized by the liquid pump, stabilized, and measured, and the liquid is then mixed with the measured compressed gas in the test pipe section. Finally, the gas is separated by the gas-liquid separator, and the liquid returns to the oil-water mixing tank. The gas from the test pipe section is directly discharged into the atmosphere. The experimental device and process are shown in Figure 2.

The pipe section selected in the experiment has an inner diameter of $60 \mathrm{~mm}$ and a total length of $11.5 \mathrm{~m}$. A pressure sensor, temperature sensor, differential pressure sensor, quick-closing valve, and other devices are installed in the pipe section (the measurement range and system error of the devices are shown in Table 1). The distance between the two quick-closing valves is $9.5 \mathrm{~m}$ and includes a $7 \mathrm{~m}$ plexiglass pipe and a $2.5 \mathrm{~m}$ long stainless steel pipe. The drain valve is used to place the liquid into the measuring cylinder after closing the quick-closing valve to measure the volume of the liquid phase.

2.1.3. Experimental White Oil Viscosity Measuring Equipment. In this experiment, a Brookfield DV II rotary viscosimeter and Thermosel heater are used to measure the viscosity of the experimental liquid phase fluid.

\subsection{Experimental Principle}

2.2.1. Viscosity. In the experiment, the same liquid samples are obtained three times, and the measured liquid samples are heated to the set temperature by the Thermosel heater. Then, the viscosities of the three liquid samples are measured with the Brookfield DV II rotary viscometer, and the data are recorded. Finally, the average value is taken as the viscosity of the liquid at this temperature.

2.2.2. Flow Pattern. In the experiment, the flow pattern is determined by the combination of a high-speed camera installed on the test pipe section and experimental observations and is recorded and photographed. The high-speed camera (Canon Xtra NX4-S1) used to record the flow pattern is shown in Figure 3. The main parameters of this camera are as follows: the pixel resolution is $1920 \times 1080$, and the maximum frame rate is $50000 \mathrm{fps}$.

2.2.3. Differential Pressure. The differential pressure sensor installed on the test pipe section is used to measure the pressure difference when the flow is stable and to record and save 


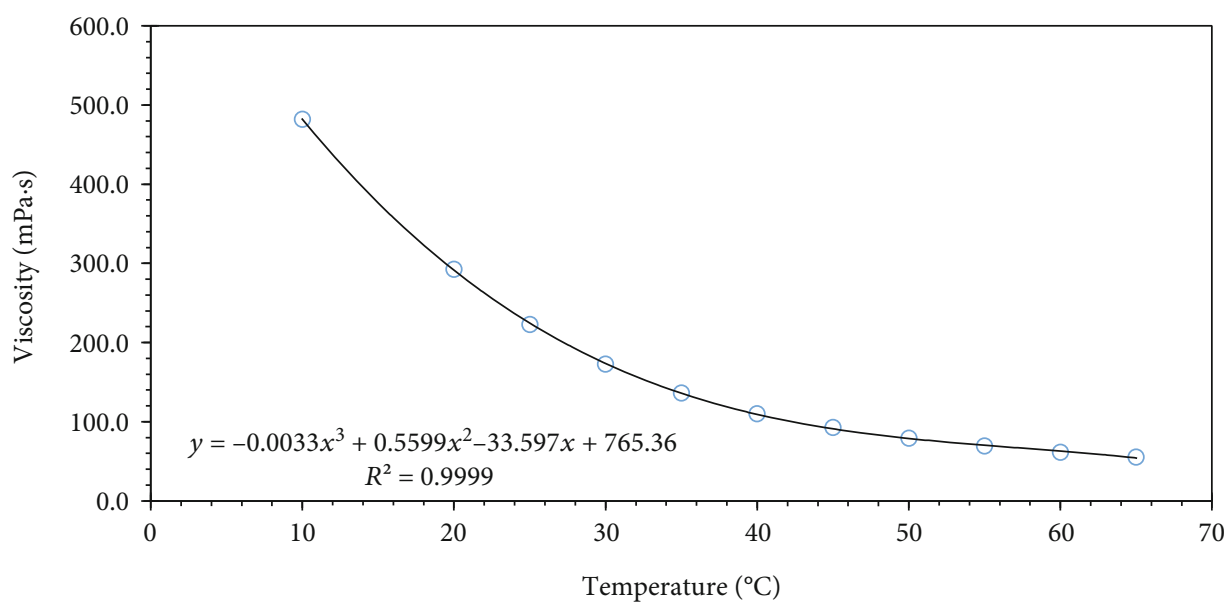

Figure 1: Viscosity vs. temperature curve of the tackifying white oil.

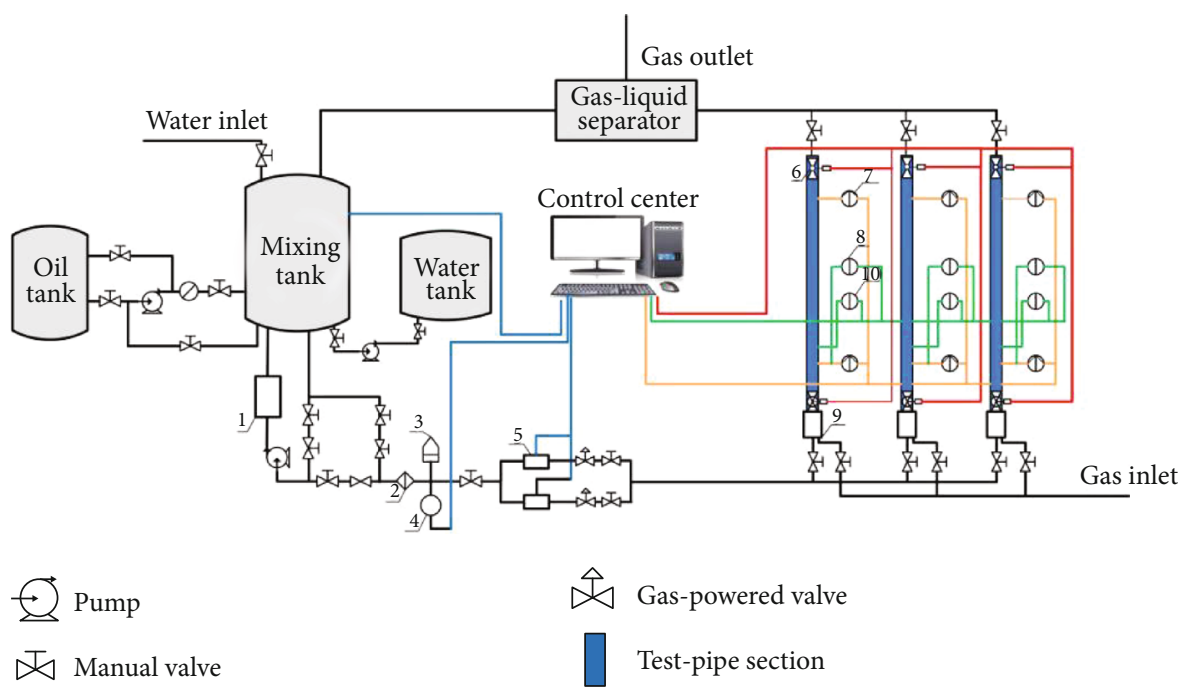

1. Water meter 2. Filter 3. Accumulator 4. Pressure sensor 5. Liquid flow meter 6. Quick-closevalve 7. Differential pressure sensor 8. Temperature-pressure sensor 9. Gas-liquid mixture 10. Temperature sensor

Figure 2: Device and process of the multiphase flow experiment.

TABle 1: Measurement ranges and system errors of each instrument.

\begin{tabular}{lcc}
\hline Device & Measurement range & System error \\
\hline Pressure sensor & $0-3.5 \mathrm{MPa}$ & $\pm 0.1 \%$ \\
Temperature sensor & $0-90^{\circ} \mathrm{C}$ & $\pm 0.5 \%$ \\
Liquid mass flowmeter & $0-20 \mathrm{~m}^{3} / \mathrm{h}$ & $\pm 0.3 \%$ \\
Gas mass flowmeter & $0-2000 \mathrm{~m}^{3} / \mathrm{h}$ & $\pm 1 \%$ \\
Differential pressure sensor & $0-0.25 \mathrm{MPa}$ & $\pm 0.25 \%$ \\
\hline
\end{tabular}

the value. To accurately measure the pressure drop in the gasliquid two-phase flow, a Rosemount 3051S differential pressure sensor is installed in the laboratory. The high-pressure and low-pressure sides of the sensor are connected to the sensor by a pipeline filled with silicone oil, as the pressure is transmitted through the highly sensitive diaphragm vibration at the high-pressure and low-pressure sides. An image of the differential pressure sensor is shown in Figure 4.

2.3. Experimental Scheme. Heavy oil refers to high-viscosity heavy crude oil with a viscosity greater than $50 \mathrm{mPa} \bullet$ s under formation conditions. This experiment is aimed at gas-liquid two-phase flow in highly inclined oil wells. Based on the viscosity characteristics of heavy oil and the characteristics of the experimental equipment, experiments on gas-liquid two-phase flow with different viscosities of $50 \mathrm{mPa} \bullet \mathrm{s}$, $100 \mathrm{mPa} \bullet \mathrm{s}, 290 \mathrm{mPa} \bullet \mathrm{s}$, and $480 \mathrm{mPa} \bullet \mathrm{s}$ are carried out. The specific experimental scheme is shown in Table 2.

2.4. Experimental Procedure. The experiment is conducted as follows:

(1) Check the state of the test device, including whether the valves are in the correct open or closed states 


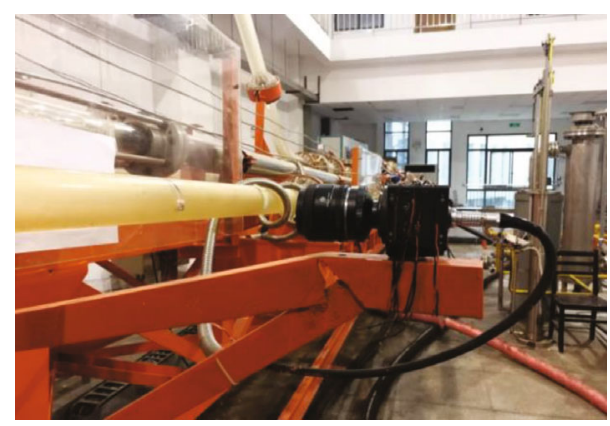

Figure 3: High-speed camera.

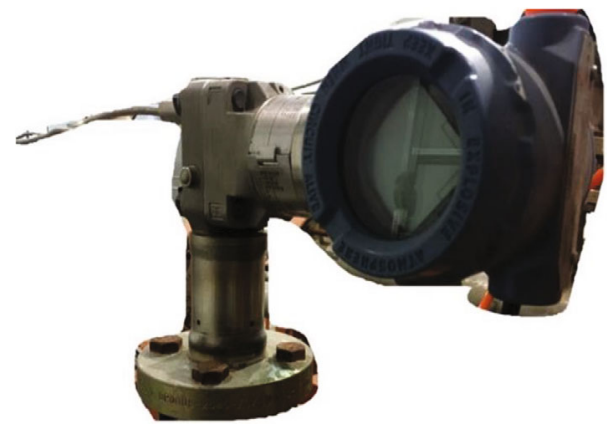

Figure 4: Differential pressure sensor.

and whether the pressure of the test pipe section is normal

(2) Turn on the cooling water system and air compressor

(3) Adjust the experimental pipe section to the angle required by the experiment through the experimental console

(4) Open the air inlet valve, adjust the air volume to a larger value to first dry the residual liquid in the pipeline, and then close the air inlet valves and clear the differential pressure

(5) Open the agitator in the oil-water mixing tank, start the electric heating, heat the liquid in the oil-water mixing tank to the predetermined temperature, open the liquid inlet valve, adjust the liquid volume to the required value, open the air inlet valve, adjust the air volume to the required value, adjust the opening of the outlet valve, and start the air heater to heat the gas to the predetermined temperature. After the temperature in the test tube reaches the experimental set value, observe the gas-liquid two-phase flow stability, start to record the data, acquire images with the high-speed camera, and then observe and record the flow pattern

(6) After data recording, first, close the liquid inlet valve and open the air inlet valve. Check whether the pressure difference in the pipe is normal and repeat the experiment outlined in step (5) after the liquid in the pipe section is blown out
(7) Close the liquid inlet valve and air inlet valve after all experiments at one inclination angle are completed and repeat the above experiments beginning with step (3)

(8) After the completion of all experiments, close the plunger pump and liquid inlet valve, increase the air volume to blow out the liquid in the test pipe section, and close the air inlet valve and air compressor. Then, restore the test pipe section to the horizontal position and turn off the computer and power supply

2.5. Analysis of Experimental Results. The total pressure drop in gas-liquid two-phase flow is composed of a gravity pressure drop and friction pressure drop. The variation in the pressure drop with viscosity is discussed in terms of three aspects: total pressure drop, gravity pressure drop, and friction pressure drop.

2.5.1. Variation in the Gravity Pressure Drop with Liquid Viscosity. The variation in the gravity pressure drop with liquid viscosity is shown in Figure 5. The figure shows that in the vertical and inclined pipes, at the same apparent gas and liquid flow rates, the gravity pressure drop increases with increasing viscosity. The main reason is that the increase in viscosity increases the viscous force between the liquid phase and the pipe wall, causing more liquid to stay on the pipe wall, which results in the increase in the liquid holdup. According to formulas (2) and (3), the gravity pressure drop is determined mainly by the liquid holdup. Therefore, the gravity pressure drop increases with increasing liquid viscosity.

2.5.2. Variation in the Friction Pressure Drop with Liquid Viscosity. The variation in the friction pressure drop with liquid viscosity is shown in Figure 6. The figure shows that in the vertical and inclined pipes, when the apparent liquid flow rate is greater than $0.16 \mathrm{~m} / \mathrm{s}$ and the apparent gas flow rate is greater than $6 \mathrm{~m} / \mathrm{s}$, the friction pressure drop increases with increasing liquid viscosity at the same apparent gas and liquid velocity. When the apparent liquid flow rate is less than $0.16 \mathrm{~m} / \mathrm{s}$ and the apparent gas flow rate is less than $6 \mathrm{~m} / \mathrm{s}$, the friction pressure drop displays a negative value because under the same apparent gas and liquid velocity, the negative value increases with increasing viscosity. The reason is that the shear force between the liquid phase and the pipe wall increases with increasing viscosity at higher apparent gas and liquid flow rates; thus, the friction pressure drop increases with increasing liquid viscosity. However, at lower apparent gas and liquid flow rates, a negative wall shear stress may exist due to the backflow of the liquid film (in the laminar state), which leads to a negative friction pressure drop. With increasing liquid viscosity, the liquid Reynolds number $\left(R_{\mathrm{ef}}=\rho_{\mathrm{l}} v_{\mathrm{f}} d / \mu_{\mathrm{l}}\right)$ in the liquid film decreases. According to the correlation formula $\left(f_{\mathrm{l}}=C / R_{\mathrm{ef}}\right)$ of the friction coefficient in laminar flow, when the Reynolds number decreases, the corresponding friction coefficient increases, which results in an increase in the negative friction pressure drop. 
TABLE 2: Experimental scheme of gas-liquid two-phase flow under different viscosities.

\begin{tabular}{lccccc}
\hline $\begin{array}{l}\text { Temperature } \\
\left({ }^{\circ} \mathrm{C}\right)\end{array}$ & $\begin{array}{c}\text { Oil viscosity } \\
(\mathrm{mPa} \bullet \mathrm{s})\end{array}$ & $\begin{array}{c}\text { Inclination angle } \\
\left({ }^{\circ}\right)\end{array}$ & $\begin{array}{c}\text { Pipe diameter } \\
(\mathrm{mm})\end{array}$ & $\begin{array}{c}\text { Apparent liquid flow rate } \\
(\mathrm{m} / \mathrm{s})\end{array}$ & $\begin{array}{c}\text { Apparent gas flow rate } \\
(\mathrm{m} / \mathrm{s})\end{array}$ \\
\hline $10,20,40,60$ & $480,290,100,50$ & 90,60 & 60 & $0.02,0.08,0.16,0.52$ & $0.2 \sim 23$ \\
\hline
\end{tabular}

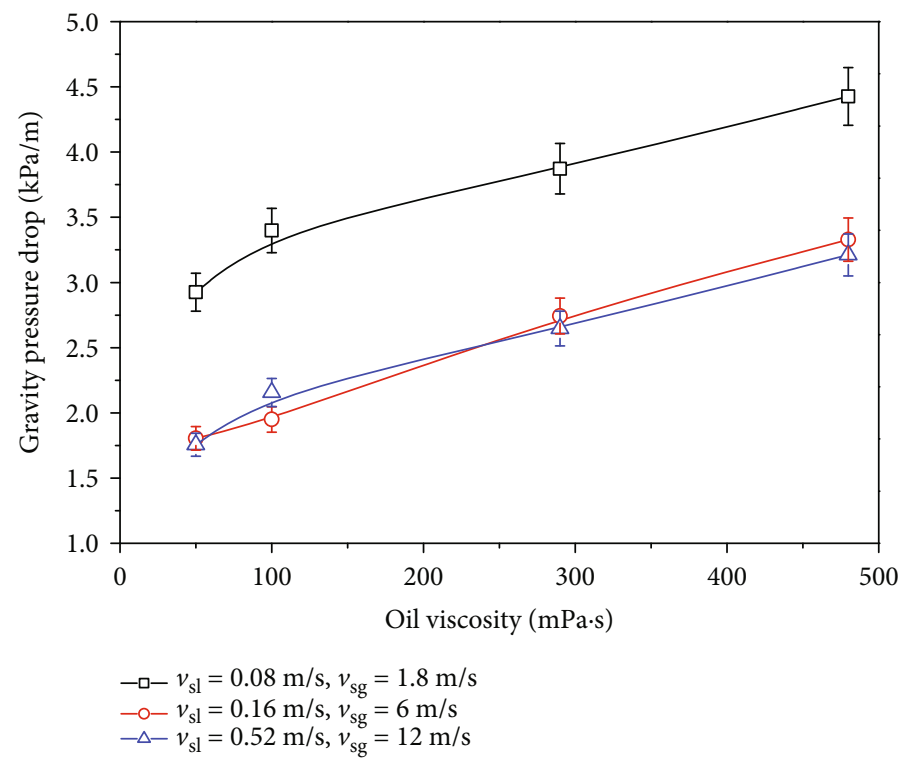

(a) Vertical pipe

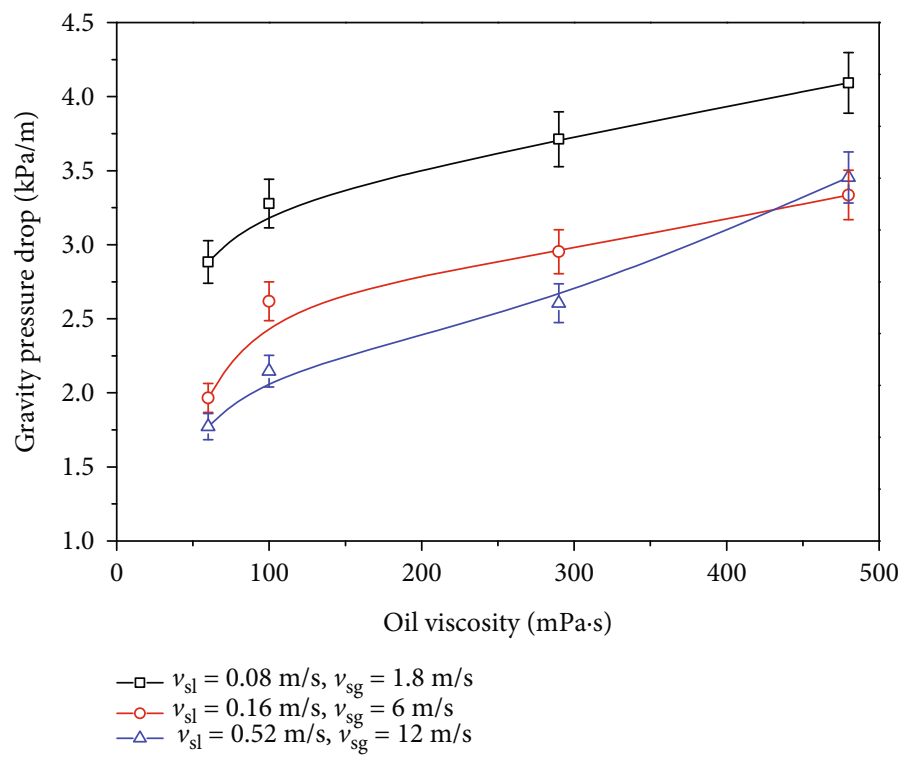

(b) Inclined pipe at 60 degrees

FIGURE 5: Variation in the gravity pressure drop with oil viscosity.

2.5.3. Variation in the Total Pressure Drop with Liquid Viscosity. The variation in the total pressure drop with liquid viscosity is shown in Figure 7. The figure shows that in the vertical and inclined pipes, when the apparent gas and liquid flow rates are the same and the apparent liquid flow rate is $0.52 \mathrm{~m} / \mathrm{s}$ and the apparent gas flow rate is $12 \mathrm{~m} / \mathrm{s}$, the total pressure drop increases with increasing liquid viscosity.
However, when the apparent gas and liquid flow rates are small and a negative friction pressure drop occurs, the negative value of the negative friction pressure drop increases with increasing viscosity of the liquid because the gravity pressure drop increases with increasing viscosity and the increased range of the total pressure drop decreases with increasing liquid viscosity. 


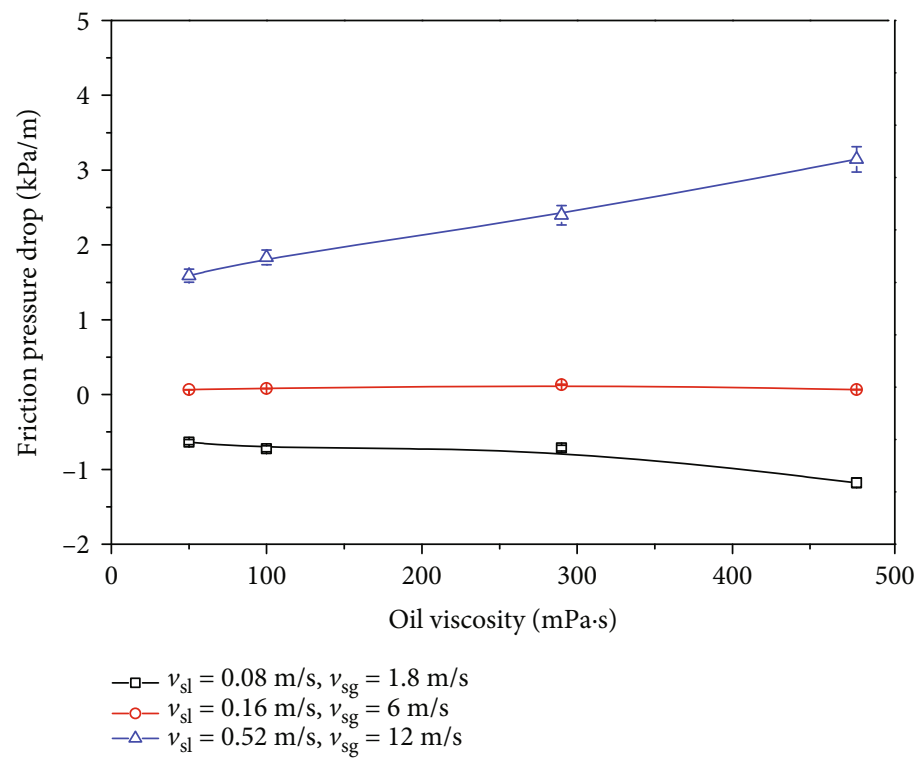

(a) Vertical pipe

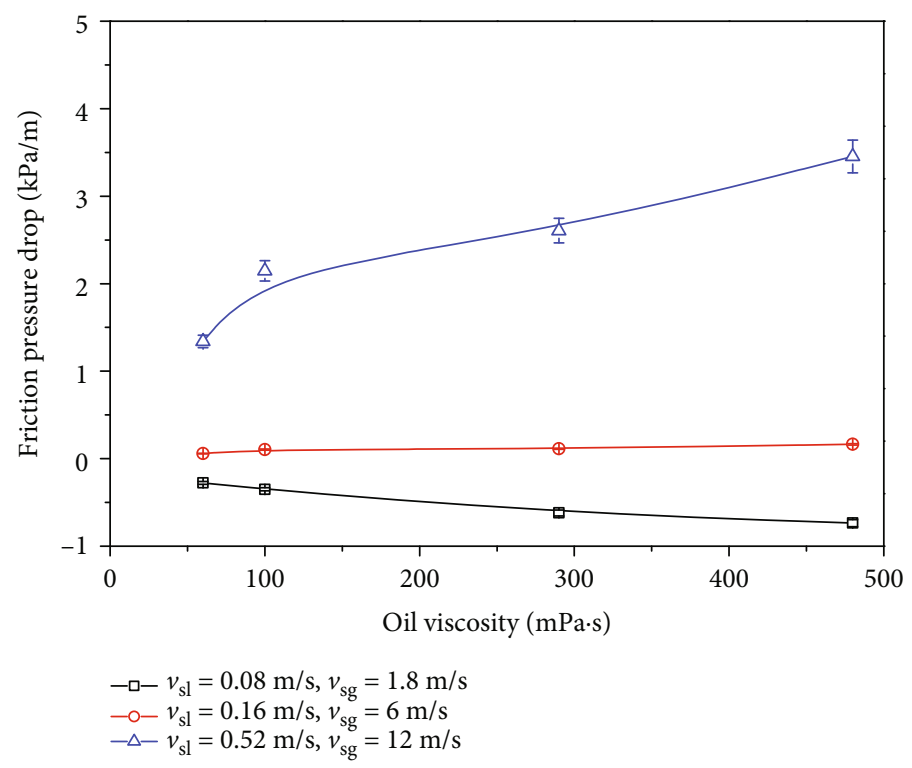

(b) Inclined pipe at 60 degrees

FIgURE 6: Variation in the friction pressure drop with oil viscosity.

\section{Prediction Model of the Pressure Drop}

\subsection{Prediction Model of the Pressure Drop in Slug Flow}

3.1.1. Gravity Pressure Drop in Slug Flow. The gravity pressure drop is mainly related to the density of the mixed fluid and the inclination of the pipeline, and the expression is described as follows:

$$
\begin{aligned}
\left(\frac{d P}{d L}\right)_{\mathrm{h}} & =\rho_{\mathrm{m}} g \sin \theta, \\
\rho_{\mathrm{m}} & =\rho_{\mathrm{l}} H_{\mathrm{l}}+\rho_{\mathrm{g}}\left(1-H_{\mathrm{l}}\right),
\end{aligned}
$$

where $\rho_{\mathrm{m}}$ is the density of the mixture in the slug body, $\mathrm{kg} / \mathrm{m}^{3} ; H_{1}$ is the liquid holding capacity of slug flow; $\rho_{1}$ is the density of the liquid phase, $\mathrm{kg} / \mathrm{m}^{3} ; \rho_{\mathrm{g}}$ is the density of the gas, $\mathrm{kg} / \mathrm{m}^{3}$; and $\theta$ is the inclination angle, .

The gravity pressure drop in slug flow is determined mainly by the liquid holdup. To consider the influence of viscosity, the liquid holdup calculation model of slug flow proposed by Liu et al. [1] is selected in this paper.

\subsubsection{Friction Pressure Drop in Slug Flow}

(1) Hydrodynamic Model of the Slug Flow Film Region. Taitel and Dukler [15] and Barnea [16] comprehensively analyzed slug flow and extended the research scope of slug flow to a 


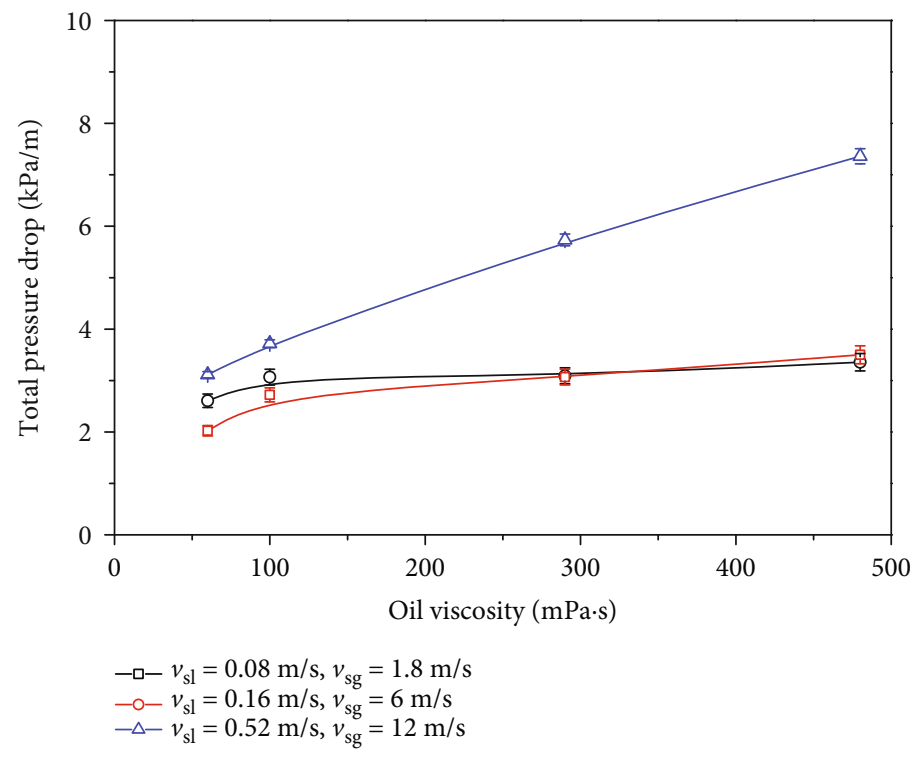

(a) Vertical pipe

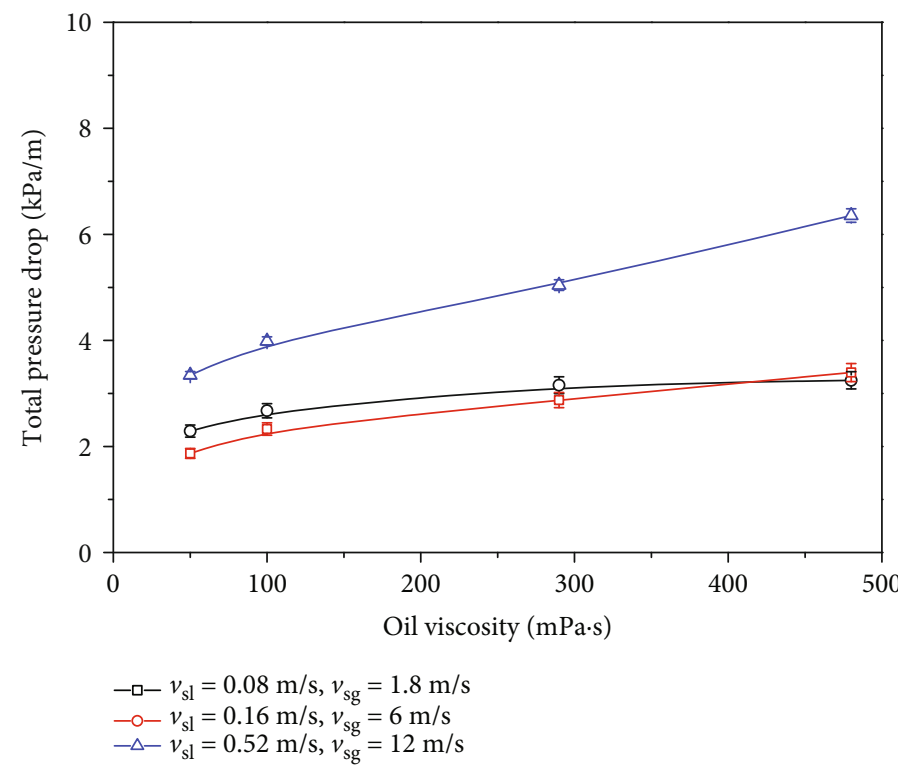

(b) Inclined pipe at 60 degrees

Figure 7: Variation in the total pressure drop with oil viscosity.

unified model of horizontal flow, upward sloping flow, and upward vertical flow.

(a) Momentum Equation of the Liquid Film Region

In the translational velocity coordinate system, the momentum equations of the liquid film region and the air plug region are expressed as follows:

$$
\frac{\partial p}{\partial z}=\frac{\tau_{\mathrm{F}} s_{\mathrm{F}}}{A_{\mathrm{F}}}-\frac{\tau_{1} s_{\mathrm{l}}}{A_{\mathrm{l}}}-\rho_{\mathrm{l}} g \sin \theta
$$

$$
\frac{\partial p}{\partial z}=\frac{\tau_{\mathrm{G}} s_{\mathrm{G}}}{A_{\mathrm{G}}}+\frac{\tau_{\mathrm{l}} s_{\mathrm{l}}}{A_{\mathrm{l}}}-\rho_{\mathrm{g}} g \sin \theta .
$$

By combining the above two formulas, we obtain the following expression:

$$
\frac{\tau_{\mathrm{F}} s_{\mathrm{F}}}{A_{\mathrm{F}}}-\frac{\tau_{\mathrm{G}} s_{\mathrm{G}}}{A_{\mathrm{G}}}-\tau_{1} s_{1}\left(\frac{1}{A_{\mathrm{l}}}+\frac{1}{A_{\mathrm{G}}}\right)+\left(\rho_{\mathrm{l}}-\rho_{\mathrm{g}}\right) g \sin \theta,
$$

where $\tau_{\mathrm{F}}$ is the shear force in the liquid film region, $\mathrm{N} ; \tau_{\mathrm{G}}$ is the shear force in the air plug region, $N ; \tau_{1}$ is the shear force in the gas-liquid interface, $\mathrm{N} ; s_{\mathrm{F}}$ is the perimeter of the liquid film region, $\mathrm{m} ; s_{\mathrm{G}}$ is the perimeter of the gas plug region, $\mathrm{m} ; s_{\mathrm{l}}$ is the length of the gas-liquid interface, $\mathrm{m} ; A_{\mathrm{F}}$ is the cross- 

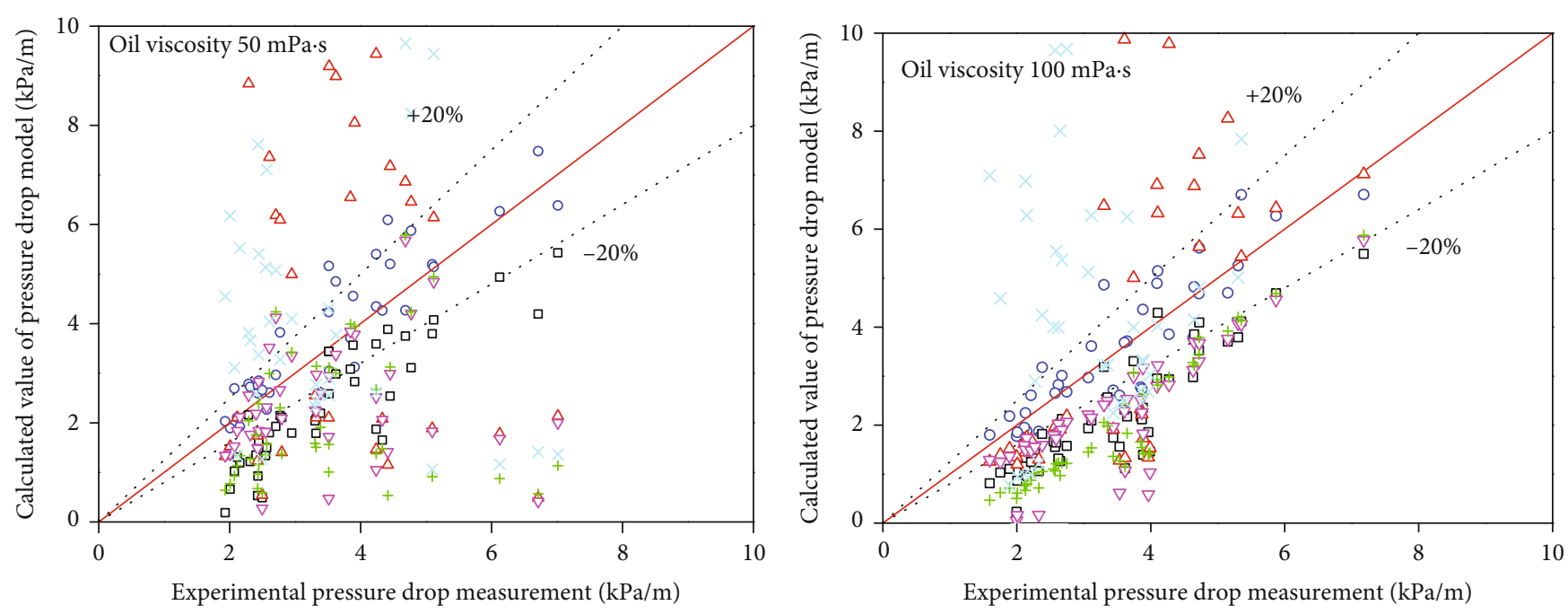
Beggs-Brill
+ JPI
$\triangle$ Aziz
Kaya

Beggs-Brill

$\triangle$ Aziz

JPI

$\nabla$ Hasan

Kaya

- New model

(a) $50 \mathrm{mPa} \bullet \mathrm{s}$

(b) $100 \mathrm{mPa} \bullet \mathrm{s}$

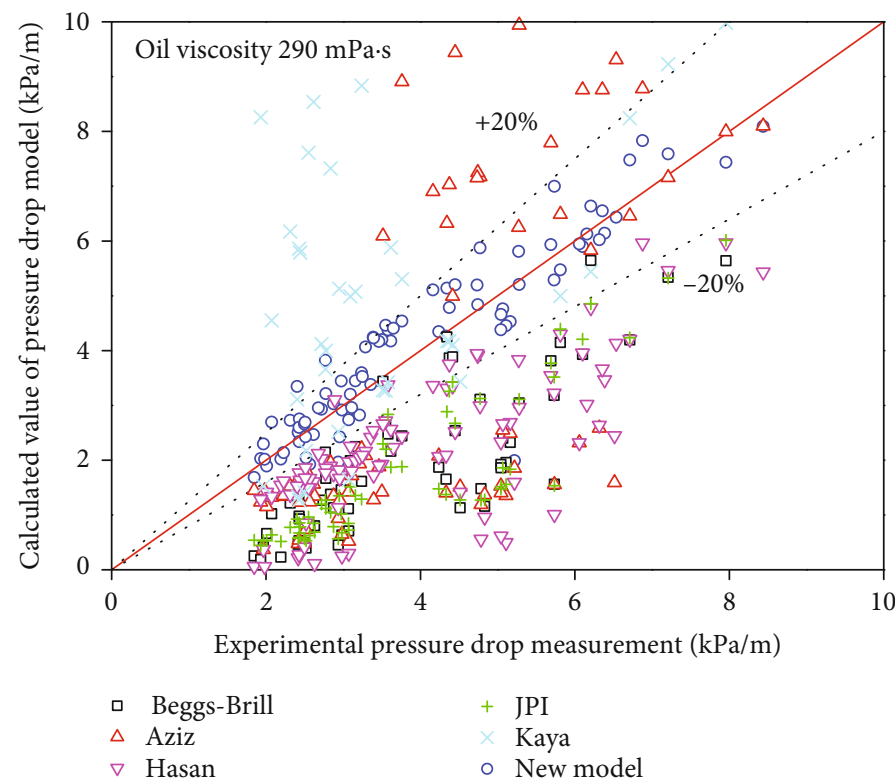

(c) $290 \mathrm{mPa} \bullet \mathrm{s}$

Figure 8: Continued. 


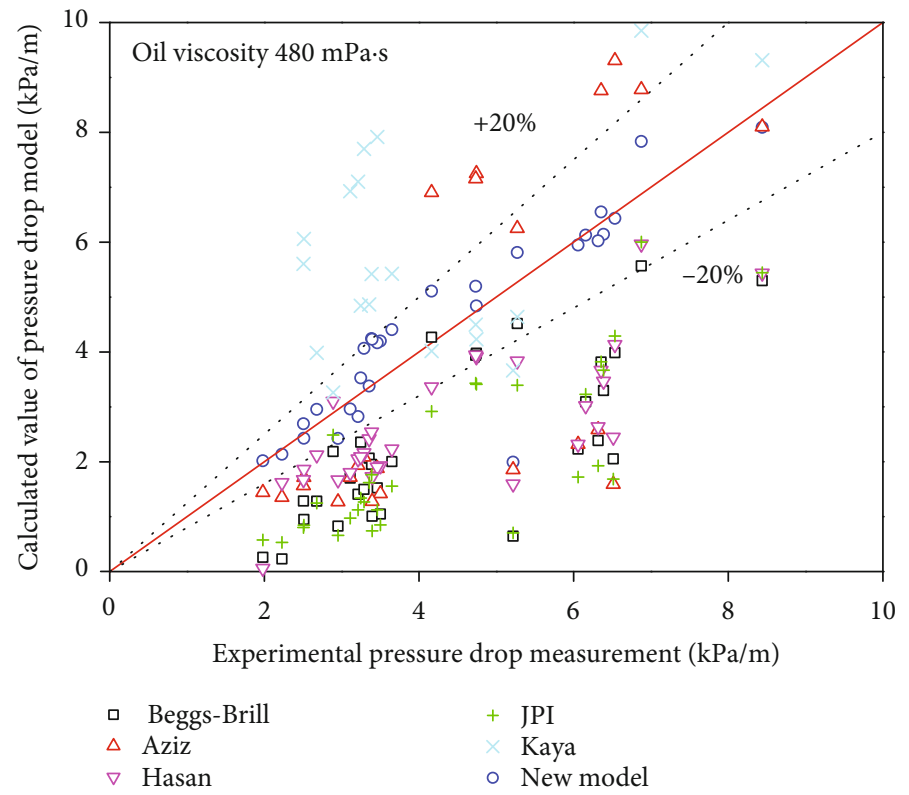

(d) $480 \mathrm{mPa} \bullet \mathrm{s}$

FIGURE 8: Comparison between calculated values of different models and experimentally measured values in slug flow.

sectional area of the liquid membrane, $\mathrm{m}^{2} ; A_{\mathrm{G}}$ is the crosssectional area of the gas plug, $\mathrm{m}^{2}$; and $A_{1}$ is the crosssectional area of the gas-liquid interface, $\mathrm{m}^{2}$.

$$
\begin{aligned}
& \tau_{\mathrm{F}}=f_{\mathrm{F}} \frac{\rho_{\mathrm{l}}\left|v_{\mathrm{LTB}}\right| v_{\mathrm{LTB}}}{2}, \\
& \tau_{\mathrm{G}}=f_{\mathrm{G}} \frac{\rho_{\mathrm{g}}\left|v_{\mathrm{GTB}}\right| v_{\mathrm{GTB}}}{2}, \\
& \tau_{1}=f_{1} \frac{\rho_{\mathrm{g}}\left|v_{\mathrm{GTB}}-v_{\mathrm{LTB}}\right|\left(v_{\mathrm{GTB}}-v_{\mathrm{LTB}}\right)}{2},
\end{aligned}
$$

where $f_{\mathrm{F}}$ is the friction coefficient of the liquid film and pipeline wall; $f_{\mathrm{G}}$ is the friction coefficient of the gas plug and pipeline wall; $f_{1}$ is the friction coefficient of the gas-liquid interface; $v_{\mathrm{LTB}}$ is the liquid flow velocity in the liquid film region, $\mathrm{m} / \mathrm{s}$; and $v_{\mathrm{GTB}}$ is the gas flow velocity in the gas plug region, $\mathrm{m} / \mathrm{s}$.

$$
f_{\mathrm{F}}=C\left(\frac{\rho_{\mathrm{l}} d_{\mathrm{F}} v_{\mathrm{LTB}}}{\mu_{\mathrm{l}}}\right)^{-n},
$$

where hydraulic diameter $d_{\mathrm{F}}=4 A_{\mathrm{F}} / S_{\mathrm{F}}$.

The friction coefficient of the gas phase can also be calculated by the same method, but $d_{\mathrm{g}}=4 A_{\mathrm{g}} /\left(S_{\mathrm{g}}+S_{\mathrm{l}}\right)$. For laminar flow, $C=16$ and $n=1$; for turbulent flow, $C=0.046$ and $n$ $=0.2$.

It is complex to determine the friction coefficient of the gas-liquid interface. For low liquid and gas velocities, the smooth interface friction coefficient can be applied, i.e., $f_{1}$ $=f_{\mathrm{g}}$. For upward flow, the friction coefficient of the gasliquid interface can be expressed as follows:

$$
f_{1}=0.005\left(1+300 \frac{h_{\mathrm{F}}}{D}\right) \text {, }
$$

where $h_{\mathrm{F}}$ is the thickness of the liquid film, $\mathrm{m}$.

(b) Determination of Flow Parameters in the Liquid Film Region

For the given flow conditions, including the apparent liquid velocity, the apparent gas velocity, the physical properties of the fluid, the diameter of the pipe, and the inclination angle, the momentum equation in the liquid film region can be solved by combining the relevant closed relations. This equation is an implicit equation for the film thickness $h_{\mathrm{F}}$. Therefore, an iterative calculation is needed in the process of solving the equation:

(1) First, based on the flow variables and the slug flow holdup calculation method, the slug average holdup $H_{1}$ and the related parameters $v_{1}, v_{\mathrm{b}}$, and $H_{\mathrm{ls}}$ are calculated

(2) The liquid phase velocity $v_{\text {LIS }}$ in the liquid plug area is calculated, as is the closed relation equation (12)

(3) Assuming an appropriate film thickness $h_{\mathrm{F}}, H_{\mathrm{ltb}}, A_{\mathrm{F}}$, $A_{\mathrm{G}}, s_{\mathrm{F}}, s_{\mathrm{G}}$, and $d_{\mathrm{F}}$ are calculated

(4) The velocity $v_{\text {Lтв }}$ of the liquid phase in the liquid film region is calculated, as is the closed relation equation (13) 


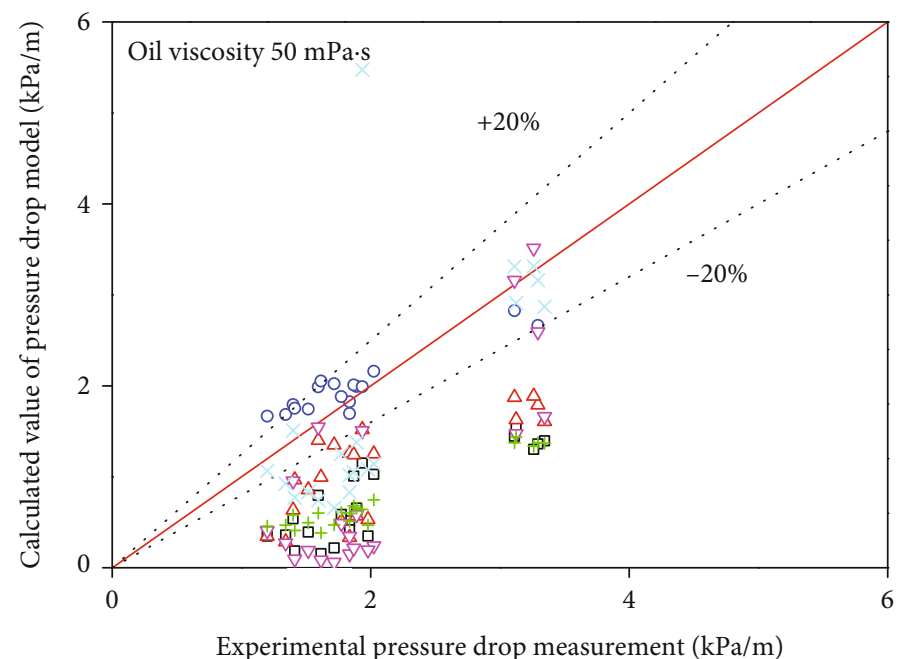
- Beggs-Brill
$\triangle$ Aziz
JPI
$\nabla$ Hasan
Kaya
- New model

(a) $50 \mathrm{mPa} \bullet \mathrm{s}$

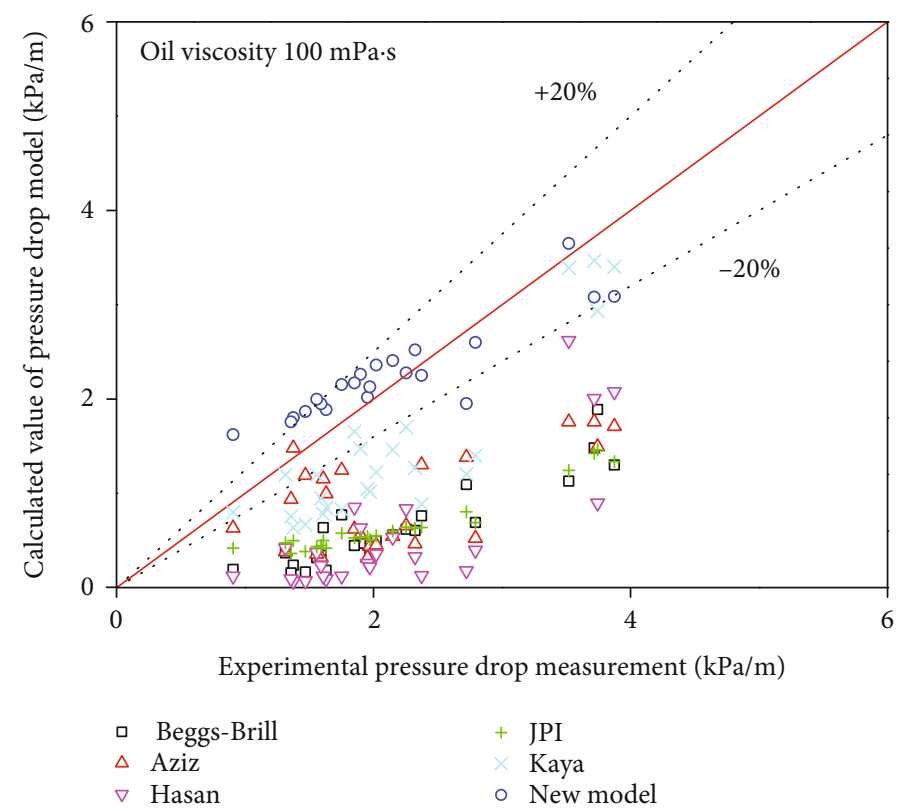

(b) $100 \mathrm{mPa} \bullet \mathrm{s}$

FIGURE 9: Continued. 


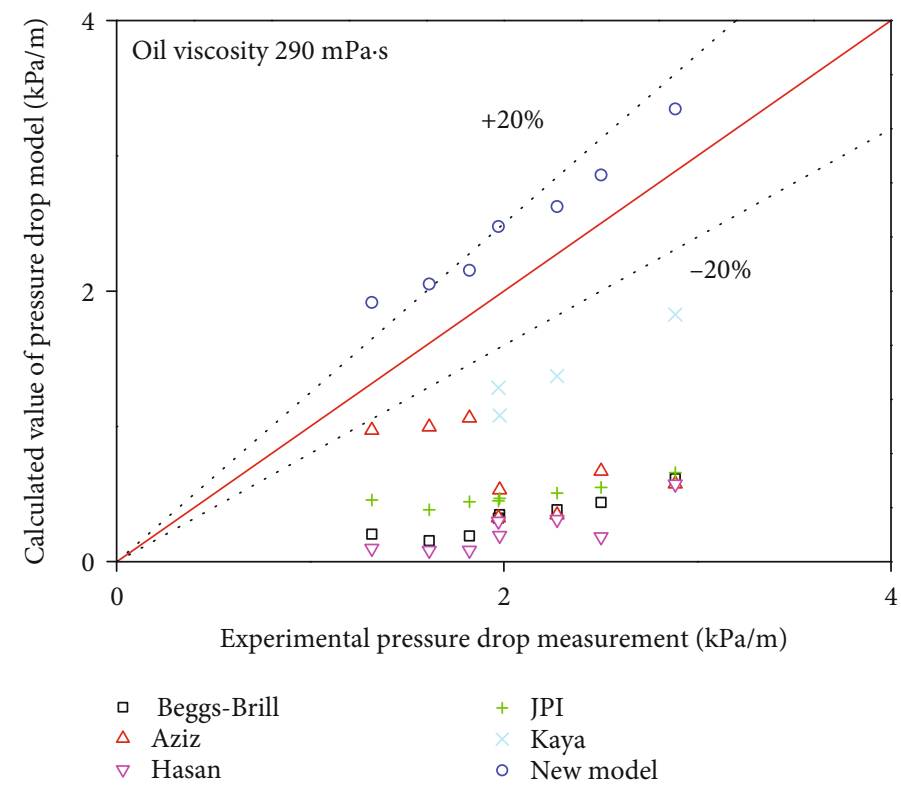

(c) $290 \mathrm{mPa} \bullet \mathrm{s}$

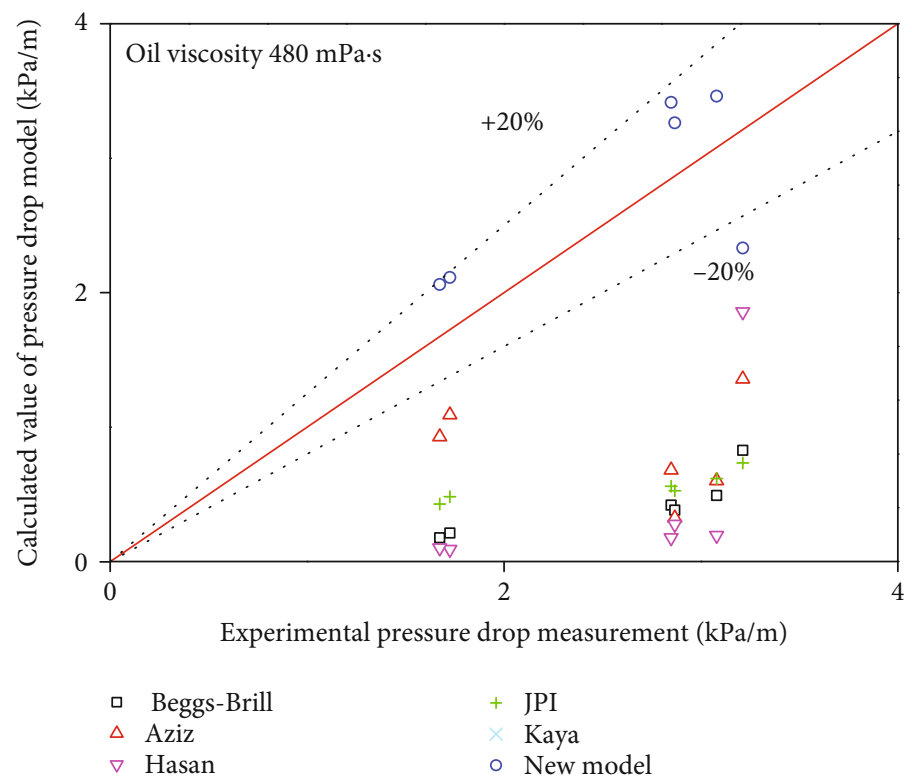

(d) $480 \mathrm{mPa} \bullet \mathrm{s}$

FIgURE 9: Comparison between calculated values of different models and experimentally measured values in agitation flow.

(5) The friction coefficient of the liquid film and pipeline wall $f_{\mathrm{F}}$, the friction coefficient of the gas plug and pipeline wall $f_{\mathrm{G}}$, and the friction coefficient of the gas-liquid interface $f_{1}$ are calculated

(6) The shear force $\tau_{\mathrm{F}}$ in the liquid film region, the shear force $\tau_{\mathrm{G}}$ in the gas plug region, and the shear force $\tau_{1}$ at the gas-liquid interface are calculated

(7) A step is performed to check whether the momentum equation converges. If it does not converge, steps (3) to (6) are repeated until it converges

\section{(c) Correlation Closed Relation}

The equation for calculating the liquid phase velocity $v_{\text {LLS }}$ in the liquid plug region is expressed as follows:

$$
v_{\mathrm{LLS}}=\frac{\left[v_{\mathrm{m}}-v_{\mathrm{GLS}}\left(1-H_{\mathrm{ls}}\right)\right]}{H_{\mathrm{ls}}} .
$$

The equation for calculating $v_{\text {LTB }}$ of the liquid phase velocity in the liquid film region is expressed as follows: 


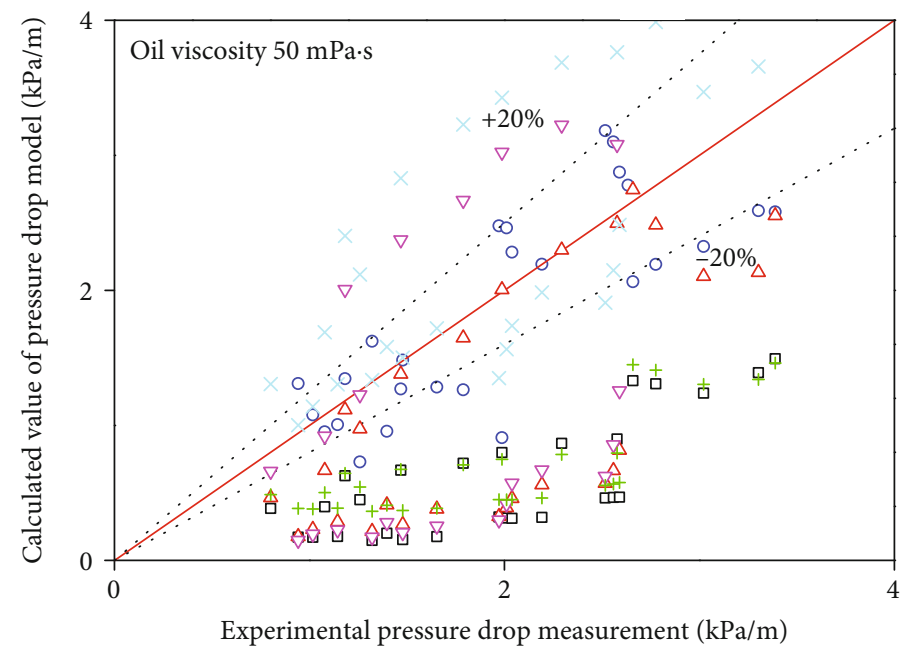
口 Beggs-Brill
+ JPI
$\triangle$ Aziz
Kaya
$\nabla$ Hasan
- New model

(a) $50 \mathrm{mPa} \bullet \mathrm{s}$

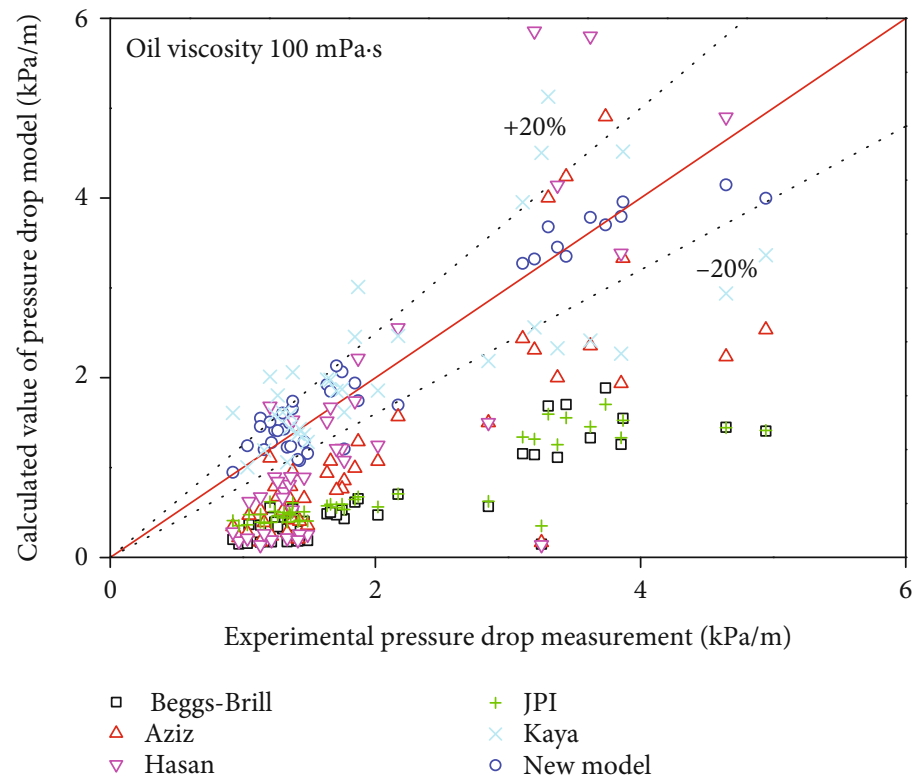

(b) $100 \mathrm{mPa} \bullet \mathrm{s}$

Figure 10: Continued. 


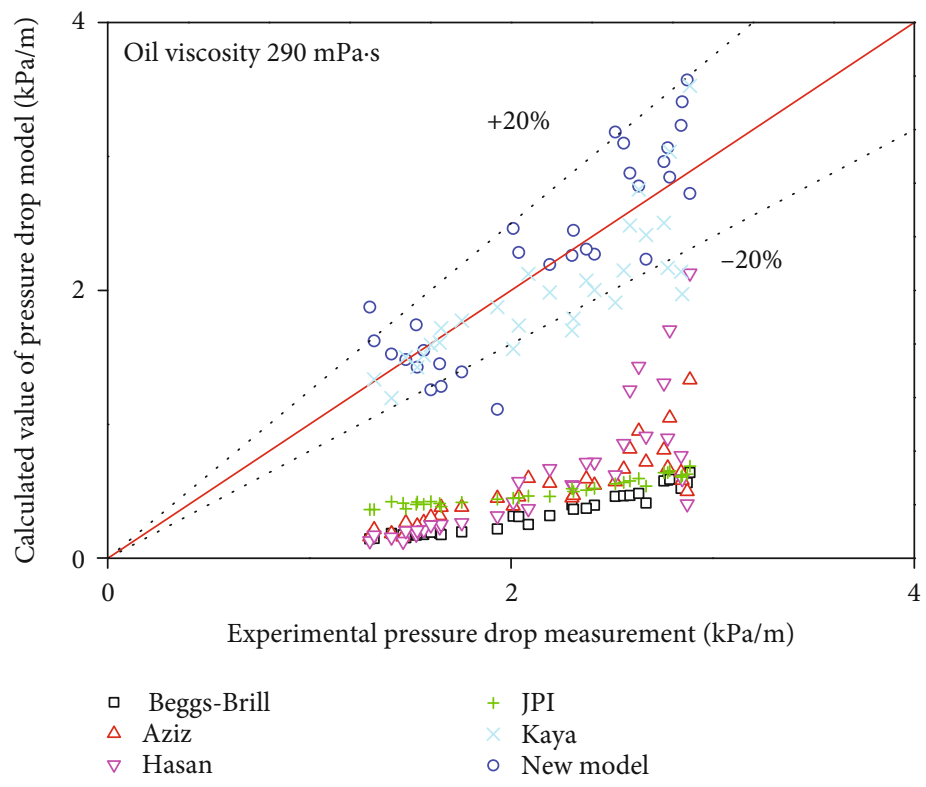

(c) $290 \mathrm{mPa} \bullet \mathrm{s}$

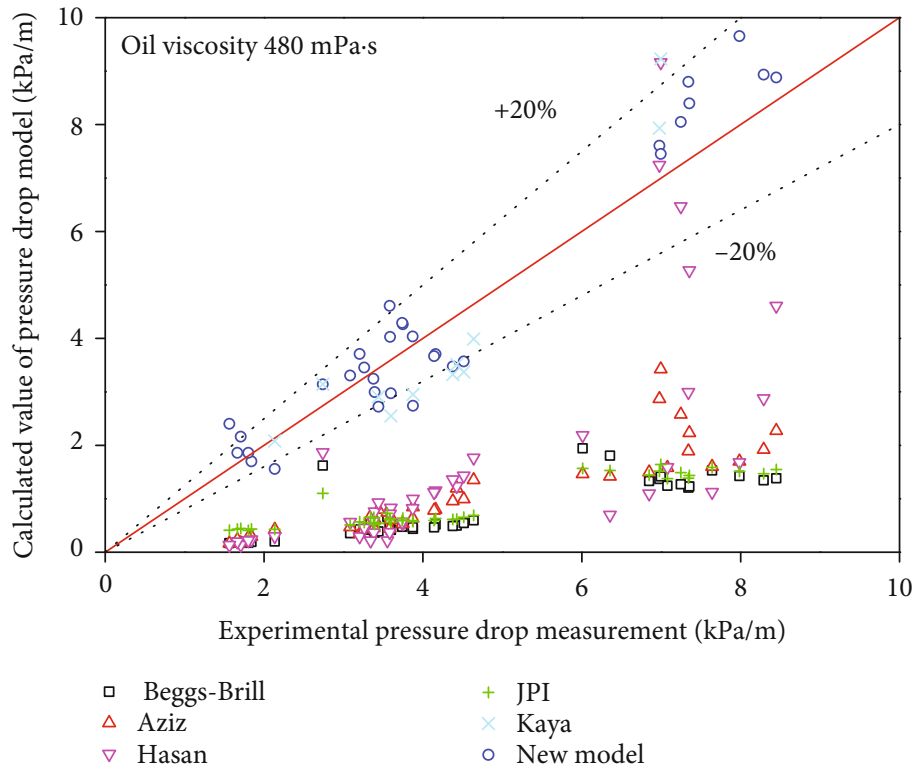

(d) $480 \mathrm{mPa} \bullet \mathrm{s}$

FIGURE 10: Comparison between calculated values of different models and experimentally measured values in annular flow.

$$
v_{\mathrm{LTB}}=v_{\mathrm{t}}-\frac{\left(v_{\mathrm{t}}-v_{\mathrm{LLS}}\right) H_{\mathrm{ls}}}{H_{\mathrm{ltb}}},
$$

where $H_{\text {ltb }}$ is the liquid holdup of the liquid film region.

The geometric relationship is expressed as follows:

$$
H_{\mathrm{ltb}}=\frac{1}{\pi}\left[\pi-\cos ^{-1}\left(2 \frac{h_{\mathrm{F}}}{d}-1\right)+\left(2 \frac{h_{\mathrm{F}}}{d}-1\right) \sqrt{1-\left(2 \frac{h_{\mathrm{F}}}{d}-1\right)^{2}}\right],
$$

$$
\begin{aligned}
& s_{\mathrm{F}}=d \sqrt{1-\left(2 \frac{h_{\mathrm{F}}}{d}-1\right)^{2}}, \\
& s_{\mathrm{g}}=\pi d-s_{\mathrm{F}}, \\
& A_{\mathrm{F}}=A_{\mathrm{p}} H_{\mathrm{ltb}}, \\
& A_{\mathrm{G}}=A_{\mathrm{p}}-A_{\mathrm{F}} .
\end{aligned}
$$

(2) Calculation of the Friction Pressure Drop in Slug Flow. In slug flow, the liquid film in the liquid plug region flows upward because the liquid phase in the liquid film region 
TABLE 3: Error percentages of different pressure drop models.

\begin{tabular}{|c|c|c|c|c|c|c|c|c|}
\hline Flow pattern & Viscosity & Error & B-B & Aziz & Hasan & JPI & Kaya & New model \\
\hline \multirow{8}{*}{ Slug flow } & \multirow{2}{*}{$50 \mathrm{mPa} \cdot \mathrm{s}$} & AAPE (\%) & 35.8 & 200.9 & 33.3 & 47.2 & 118.5 & 12.8 \\
\hline & & APE (\%) & 35.8 & -167.2 & 33.3 & 47.2 & -95.1 & -6.5 \\
\hline & \multirow{2}{*}{$100 \mathrm{mPa} \bullet \mathrm{s}$} & AAPE (\%) & 38.3 & 196.9 & 37.0 & 48.7 & 107.3 & 12.2 \\
\hline & & APE (\%) & 38.2 & -163.5 & 37.0 & 48.7 & -84.3 & 0.02 \\
\hline & \multirow{2}{*}{$290 \mathrm{mPa} \bullet \mathrm{s}$} & AAPE (\%) & 51.5 & 154.0 & 46.9 & 57.9 & 251.3 & 12.3 \\
\hline & & APE (\%) & 51.5 & -88.6 & 46.9 & 57.9 & -241.3 & -4.4 \\
\hline & \multirow{2}{*}{$480 \mathrm{mPa} \bullet \mathrm{s}$} & AAPE (\%) & 48.1 & 143.3 & 40.1 & 55.4 & 166.8 & 11.9 \\
\hline & & APE (\%) & 48.0 & -91.7 & 39.6 & 55.4 & -163.0 & -3.6 \\
\hline \multirow{8}{*}{ Agitation flow } & \multirow{2}{*}{$50 \mathrm{mPa} \bullet \mathrm{s}$} & AAPE (\%) & 65.4 & 47.5 & 61.4 & 64.8 & 72.5 & 13.9 \\
\hline & & APE (\%) & 65.4 & 47.5 & 60.5 & 64.8 & -19.0 & -6.5 \\
\hline & \multirow{2}{*}{$100 \mathrm{mPa} \bullet \mathrm{s}$} & AAPE (\%) & 73.0 & 56.3 & 78.0 & 69.3 & 34.9 & 15.3 \\
\hline & & APE (\%) & 73.0 & 55.7 & 78.0 & 69.3 & 34.9 & -4.2 \\
\hline & \multirow{2}{*}{$290 \mathrm{mPa} \bullet \mathrm{s}$} & AAPE (\%) & 84.3 & 62.6 & 89.6 & 75.4 & 404.2 & 19.4 \\
\hline & & APE (\%) & 84.3 & 62.6 & 89.6 & 75.4 & -365.1 & -19.4 \\
\hline & \multirow{2}{*}{$480 \mathrm{mPa} \bullet \mathrm{s}$} & AAPE (\%) & 84.5 & 64.0 & 84.8 & 77.6 & 594.8 & 19.8 \\
\hline & & APE (\%) & 84.5 & 64.0 & 84.8 & 77.6 & -594.8 & -10.7 \\
\hline \multirow{8}{*}{ Annular flow } & \multirow{2}{*}{$50 \mathrm{mPa} \bullet \mathrm{s}$} & AAPE (\%) & 66.5 & 43.7 & 69.3 & 60.3 & 115 & 14.6 \\
\hline & & APE (\%) & 66.5 & 40.2 & 0.1 & 60.3 & 110 & -9.7 \\
\hline & \multirow{2}{*}{$100 \mathrm{mPa} \bullet \mathrm{s}$} & AAPE (\%) & 71.7 & 50.6 & 63.3 & 63.9 & 35 & 13.8 \\
\hline & & APE (\%) & 71.7 & 47.2 & 6.1 & 63.9 & -35 & -0.7 \\
\hline & \multirow{2}{*}{$290 \mathrm{mPa} \bullet \mathrm{s}$} & AAPE (\%) & 82.6 & 73.0 & 69.8 & 75.5 & 164 & 14.5 \\
\hline & & APE (\%) & 82.6 & 73.0 & 61.9 & 75.5 & -148 & 10.6 \\
\hline & \multirow{2}{*}{$480 \mathrm{mPa} \bullet \mathrm{s}$} & AAPE (\%) & 84.1 & 79.2 & 72.4 & 80.6 & 782 & 14.3 \\
\hline & & APE (\%) & 84.1 & 79.2 & 70.8 & 80.6 & -774 & 1.6 \\
\hline
\end{tabular}

TABLE 4: Viscosity data of dead oil at different temperatures.

\begin{tabular}{|c|c|c|c|c|c|c|c|c|c|c|c|}
\hline Temperature $\left({ }^{\circ} \mathrm{C}\right)$ & 15.6 & 18.3 & 21.1 & 23.9 & 26.7 & 30.0 & 33.3 & 36.7 & 40.0 & 43.3 & 46.7 \\
\hline Viscosity $(\mathrm{mPa} \bullet \mathrm{s})$ & 482.3 & 395.2 & 324.6 & 269.0 & 225.4 & 180.0 & 146.4 & 123.3 & 102.4 & 85.0 & 73.0 \\
\hline
\end{tabular}

flows downward. The friction pressure drop in the whole slug unit can be expressed as follows:

$$
\begin{aligned}
-d p & =\frac{\tau_{\mathrm{s}} \pi d}{A_{\mathrm{p}}} L_{\mathrm{s}}+\frac{\tau_{\mathrm{F}} S_{\mathrm{F}}}{A_{\mathrm{p}}} L_{\mathrm{F}}+\frac{\tau_{\mathrm{g}} S_{\mathrm{g}}}{A_{\mathrm{p}}} L_{\mathrm{F}}, \\
\tau_{\mathrm{s}} & =f_{\mathrm{s}} \frac{\rho_{\mathrm{l}}\left|v_{\mathrm{ls}}\right| v_{\mathrm{ls}}}{2}, \\
f_{\mathrm{s}} & =C\left(\frac{\rho_{\mathrm{l}} d v_{\mathrm{ls}}}{\mu_{\mathrm{l}}}\right)^{-n},
\end{aligned}
$$

where $v_{\mathrm{ls}}$ is the average velocity of the liquid film along the pipe wall, $\mathrm{m}$. In this paper, $v_{\mathrm{ls}}=v_{\mathrm{LLS}} / 2$.

The length of the liquid plug region is as follows:

$$
L_{\mathrm{s}}=20 d \sin \theta+30 d \cos \theta \text {. }
$$

The length of the slug unit is as follows:

$$
L_{\mathrm{U}}=\frac{L_{\mathrm{s}}\left(v_{\mathrm{LLS}} H_{\mathrm{ls}}-v_{\mathrm{LTB}} H_{\mathrm{ltb}}\right)}{v_{\mathrm{sl}}-v_{\mathrm{LTB}} H_{\mathrm{ltb}}}
$$

The length of the liquid film region is as follows:

$$
L_{\mathrm{F}}=L_{\mathrm{U}}-L_{\mathrm{s}}
$$

\subsection{Prediction Model of the Pressure Drop in Agitation Flow}

3.2.1. Gravity Pressure Drop in Agitation Flow. The expression for the gravity pressure drop is the same as equations (2) and (3). The characteristics of agitation flow oscillate up and down, and the research on its flow characteristics is inadequate. For the convenience of calculation, the slug holdup model selected in this paper is used to calculate the holdup in agitation flow to calculate the gravity pressure drop in agitation flow. 
TABLE 5: Basic parameters of well XXXX-004.

\begin{tabular}{lcccc}
\hline Oil well type & $\begin{array}{c}\text { Middle depth of the } \\
\text { oil layer }(\mathrm{m})\end{array}$ & Tubing size & Casing size & Bubble point pressure (MPa) \\
Straight well & 3487 & $4^{1 /}{ }^{\prime \prime}+3^{1 /}{ }^{\prime \prime}$ & $9^{5 /}{ }^{\prime \prime}+7^{\prime \prime}$ & 18.34 \\
Water content $(\%)$ & Gas oil ratio & Relative density of water & API gravity of crude oil & $\begin{array}{c}\text { Relative density of } \\
\text { natural gas }\end{array}$ \\
0 & 52.97 & 1.13 & 17.68 & 0.99 \\
Production $\left(\mathrm{m}^{3} / \mathrm{d}\right)$ & Wellhead oil pressure $(\mathrm{MPa})$ & $\begin{array}{c}\text { Bottom hole flow } \\
\text { pressure }(\mathrm{MPa})\end{array}$ & Wellhead temperature $\left({ }^{\circ} \mathrm{C}\right)$ & Bottom hole temperature $\left({ }^{\circ} \mathrm{C}\right)$ \\
550.56 & 7.48 & 27.46 & 20 & 96
\end{tabular}

3.2.2. Friction Pressure Drop in Agitation Flow. The friction pressure drop changes from a negative friction pressure drop to a positive friction pressure drop with increasing apparent gas velocity. Analysis of the characteristics of agitation flow indicates that the flow pattern is agitation flow when the friction pressure drop is 0 . The friction pressure drop in slug flow established in this paper can be used to predict the negative and positive friction pressure drops. Therefore, the friction pressure drop model of slug flow is used to calculate the friction pressure drop in agitation flow: $(d P / d L)_{\mathrm{f}}$.

\subsection{Prediction Model of the Pressure Drop in Annular Flow}

3.3.1. Gravity Pressure Drop in Annular Flow. Similarly, the method for calculating the gravity pressure drop is the same as that for slug flow and agitation flow. The difference is that the liquid holdup of annular flow is determined by the calculation method given in this paper.

The model for calculating the liquid holdup of upward annular flow can be divided into an empirical model and a mechanistic model. Because the mechanistic model must iteratively calculate the thickness of the liquid film around the pipe wall, the equation has difficulty converging in the iterative calculation process, and the calculation results are often quite different from the actual values. Therefore, the method for calculating the liquid holdup in annular flow is obtained by fitting the experimental data based on the empirical formula of the liquid holdup.

The main purpose of this paper is to provide a model of gas-liquid two-phase flow suitable for different viscosities. Therefore, the influence of viscosity should be considered in the empirical model. The empirical formula given by Mukherjee and Brill [17] includes dimensionless parameters that consider viscosity. Therefore, we choose to modify the empirical constant in the relationship.

The relevant formula of Mukherjee and Brill is described as follows:

$$
\begin{aligned}
& H_{1}=\exp \left[\left(c_{1}+c_{2} \sin \theta+c_{3} \sin ^{2} \theta+c_{4} N_{1}^{2}\right) \frac{N_{\mathrm{vg}}^{c_{5}}}{N_{\mathrm{vl}} c_{6}}\right], \\
& N_{\mathrm{vl}}=v_{\mathrm{sl}}\left(\frac{\rho_{\mathrm{l}}}{g \sigma}\right)^{0.25},
\end{aligned}
$$

$$
\begin{aligned}
& N_{\mathrm{vg}}=v_{\mathrm{sg}}\left(\frac{\rho_{\mathrm{l}}}{g \sigma}\right)^{0.25}, \\
& N_{\mu \mathrm{l}}=\mu_{\mathrm{l}}\left(\frac{g}{\rho_{\mathrm{l}} \sigma^{3}}\right)^{0.25} .
\end{aligned}
$$

Fitting the relationship between the liquid holdup $H_{1}$ measured in the experiment and the $N_{\mathrm{vl}}, N_{\mathrm{vg}}$, and $N_{\mu \mathrm{l}}$ of the correlation standard number given by Mukherjee and Brill, the new empirical coefficients $c_{1}-c_{6}$ are $-0.131,0.064$, $-0.0475,0.0057,0.6$, and 0.099 , respectively.

\subsubsection{Friction Pressure Drop in Annular Flow}

(1) Physical Model of Annular Flow. Alves et al. [18] established a vertical tube and a large inclined angle annular flow model. The annular liquid film flows upward at a certain speed along the pipe wall, and the liquid drop in the middle moves upward with the gas. The shear stress of the tube wall to the liquid film is opposite to the moving direction of the liquid film, so it is impossible for the annular flow to have a negative friction pressure drop.

(2) Annular Flow Friction Pressure Drop. According to the flow characteristics of annular flow, only the friction pressure drop between the upward flowing liquid film and the wall surface must be calculated, which is the friction pressure drop in the annular flow. The friction pressure drop in the liquid film area can be expressed as follows:

$$
\begin{aligned}
\left(\frac{\partial p}{\partial L}\right)_{\mathrm{f}} & =-\tau_{\mathrm{WL}} \frac{s_{\mathrm{F}}}{A_{\mathrm{F}}}, \\
\tau_{\mathrm{WL}} & =f_{1} \frac{\rho_{\mathrm{l}} \nu_{\mathrm{F}}^{2}}{2}, \\
f_{\mathrm{l}} & =C\left(\frac{\rho_{\mathrm{l}} d \nu_{\mathrm{F}}}{\mu_{\mathrm{l}}}\right)^{-n},
\end{aligned}
$$

where $\tau_{\mathrm{WL}}$ is the shear stress between the liquid phase and the pipe wall; $s_{\mathrm{F}}$ is the perimeter of the liquid film, $\mathrm{m} ; A_{\mathrm{F}}$ is the sectional area of the liquid film, $\mathrm{m}^{2}$; and $v_{\mathrm{F}}$ is the velocity of the liquid film, $\mathrm{m} / \mathrm{s}$. 

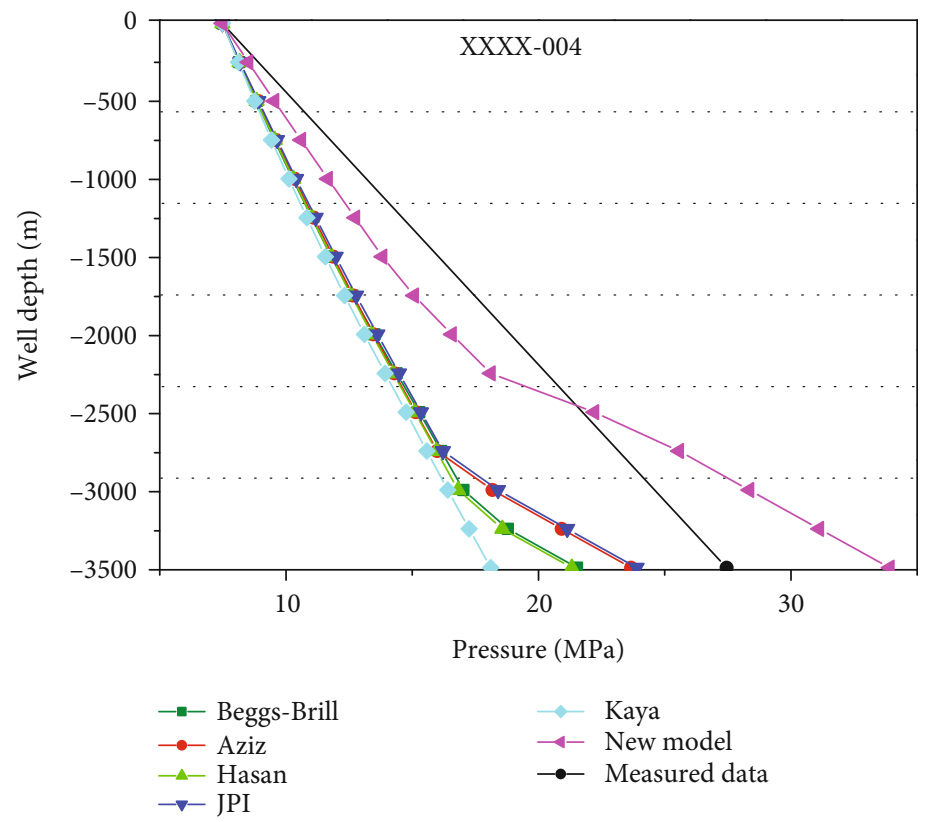

(a) Well XXXX-004

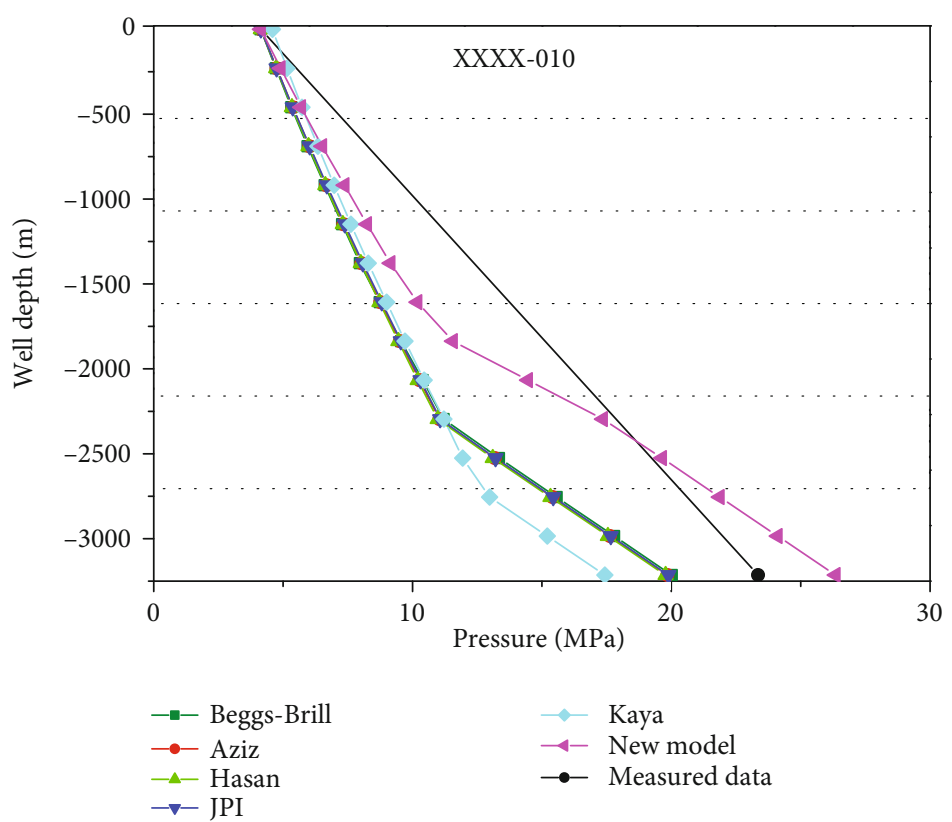

(b) Well XXXX-010

Figure 11: Continued. 


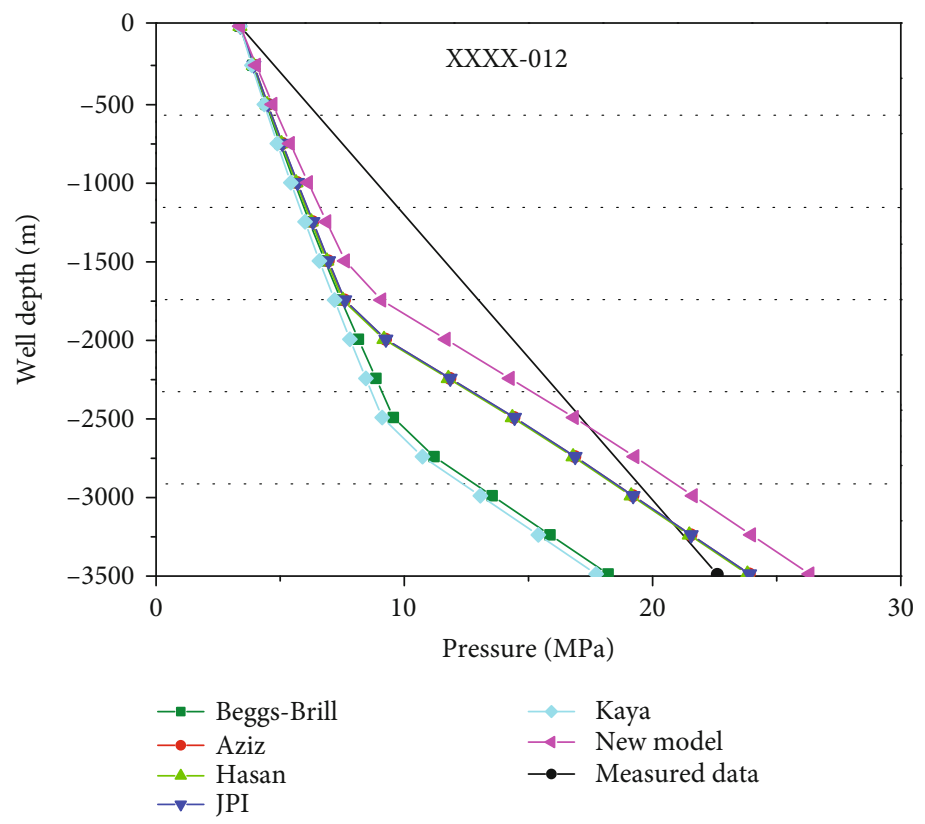

(c) Well XXXX-012

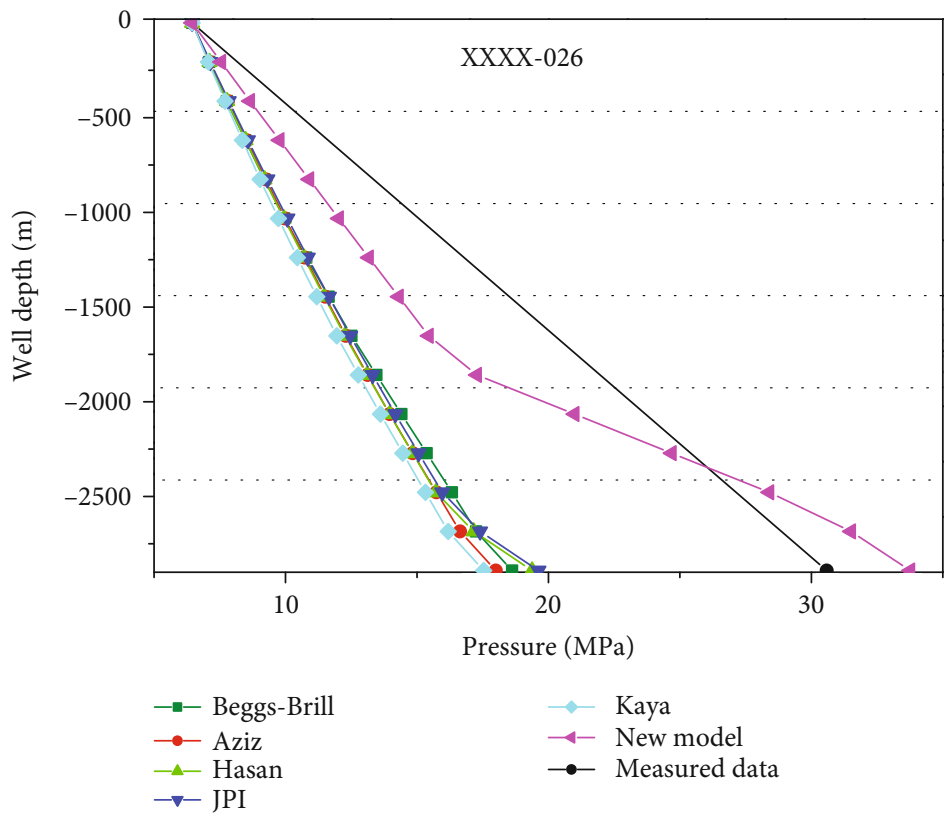

(d) Well XXXX-026

FIGURE 11: Predictions of wellbore pressure distributions by the different models.

The speed of the liquid film can be determined by a simple mass balance calculation, expressed as follows:

$$
v_{\mathrm{F}}=v_{\mathrm{sl}} \frac{\left(1-f_{\mathrm{E}}\right) d^{2}}{4 \delta_{1}\left(d-\delta_{1}\right)} .
$$

The gas and entrained droplets are assumed to flow uniformly in the gas core without slippage, and the void ratio of the gas in the gas core is expressed as follows:

$$
a_{\mathrm{C}}=\frac{v_{\mathrm{sg}}}{v_{\mathrm{sg}}+v_{\mathrm{sl}} f_{\mathrm{E}}} .
$$

The relationship between the liquid holdup and the liquid film thickness is expressed as follows:

$$
1-H_{1}=a_{\mathrm{C}}\left(1-2 \frac{\delta_{1}}{d}\right)^{2}
$$

where $\delta_{1}$ is the thickness of the liquid film, $\mathrm{m}$. 
TABLE 6: Calculation errors of the different models.

\begin{tabular}{lccccccc}
\hline Well & Error & B-B & Aziz & Hasan & JPI & Kaya & New model \\
\hline \multirow{2}{*}{ XXXX-004 } & AAPE (\%) & 25.07 & 23.01 & 25.52 & 22.28 & 28.35 & -1.23 \\
& APE (\%) & 25.07 & 23.01 & 25.52 & 22.28 & 28.35 & 12.61 \\
XXXX-010 & AAPE (\%) & 27.93 & 28.25 & 28.59 & 28.03 & 31.25 & 13.7 \\
& APE (\%) & 27.93 & 28.25 & 28.59 & 28.03 & 30.82 & 7.1 \\
XXXX-012 & AAPE (\%) & 34.28 & 19.32 & 19.59 & 19.28 & 36.4 & 36.4 \\
& APE (\%) & 34.28 & 17.68 & 18.1 & 17.61 & 38.15 & 7.04 \\
XXXX-026 & AAPE (\%) & 35.45 & 36.65 & 36.09 & 35.25 & 35.25 & 38.14 \\
& APE (\%) & 35.45 & 36.65 & 36.09 & 35.25 & 8.24 \\
\hline
\end{tabular}

The equation for calculating the entrainment rate of droplets is expressed as follows:

$$
\begin{aligned}
& f_{\mathrm{E}}=1-\exp [-0.125(\varphi-1.5)], \\
& \varphi=10^{4} \frac{v_{\mathrm{sg}} \mu_{\mathrm{g}}}{\sigma}\left(\frac{\rho_{\mathrm{g}}}{\rho_{\mathrm{l}}}\right)^{0.5} .
\end{aligned}
$$

According to the geometric relationship,

$$
\begin{aligned}
& s_{\mathrm{F}}=\pi d, \\
& A_{\mathrm{C}}=\pi\left(\frac{D}{2}-\delta_{1}\right)^{2}, \\
& A_{\mathrm{F}}=A_{\mathrm{p}}-A_{\mathrm{C}} .
\end{aligned}
$$

The method for calculating the annular flow friction pressure drop is described as follows:

(1) According to the method for calculating the liquid holdup in annular flow, after calculating the liquid holdup, the liquid film thickness $\delta_{1}$ is calculated according to the relationship between the liquid holdup and the liquid film thickness

(2) According to equation (35), the entrainment rate of the liquid $\operatorname{drop} f_{\mathrm{E}}$ is calculated

(3) According to equation (32), the liquid film velocity $v_{\mathrm{F}}$ is calculated, and the relevant geometric parameters $s_{\mathrm{F}}$ and $A_{\mathrm{F}}$ are then calculated

(4) The friction coefficient $f_{\mathrm{l}}$ is calculated according to the friction coefficient calculation method, and the shear stress $\tau_{\mathrm{WL}}$ between the liquid film and the wall is then calculated

(5) Finally, the friction pressure drop in annular flow is calculated according to equation (29)

3.4. Verification of the Pressure Drop Prediction Model. The pressure drop models of slug flow, agitation flow, and annular flow are verified by experimental data, as the existing empirical model (Beggs-Brill [19]) and mechanistic models (Aziz [20], Hasan [21], JPI [22], and Kaya [23]) are used for comparison with the model in this paper. The calculated pressure drop values of the six models with different viscosities are compared with the experimental values, and the results are shown in Figures 8-10 and Table 3.

The figure shows that compared with the experimental measurement values, the error in the pressure drop in the model established in this paper is largely within $20 \%$, which is smaller than the error of the existing five models. The calculation errors of most existing models are greater than $20 \%$, with large errors. Comparison of the pressure drop calculation errors of different models with different viscosities indicates that the errors of the existing models are relatively large and increase as the viscosity increases. The average absolute error rate of the model established in this paper is less than $15 \%$, which is accurate for the prediction of experimental data and suitable for calculating the pressure drop for slug flow, agitation flow, and annular flow with different viscosities.

\section{Case Calculation and Comparative Verification of Wellbore Pressure Distribution}

In this paper, the test data for four wells with low gas: oil ratios $\left(20 \sim 53 \mathrm{~m}^{3} / \mathrm{m}^{3}\right)$ and high production (227.2$656.3 \mathrm{~m}^{3} / \mathrm{d}$ ) in the BeiA oilfield of Iran are selected. Similarly, the wellbore pressure distribution is calculated by using the existing empirical model (Beggs-Brill), existing mechanistic models (Aziz, Hasan, JPI, and Kaya), and multiphase flow pressure drop model established in this paper.

4.1. Viscosity of Degassed Crude Oil. The viscosity of the degassed crude oil of the oilfield at different temperatures is tested under laboratory conditions. The viscosity data are shown in Table 4. The data in the table show that the crude oil of the oilfield is ordinary heavy oil, and the viscosity is similar to that of the oil used in this experiment.

4.2. Example Well Calculation. The pressure test data for the four selected oil wells are wellhead pressure and bottom hole flow pressure. The whole wellbore is divided into 14 sections, and different pressure drop models are used to calculate the wellbore pressure distribution from the wellhead to the bottom of the well. The distribution of wellbore pressure predicted by the different models is given, and the calculation results of the different models are compared. The basic 
parameters of well XXXX-004, as an example, are shown in Table 5.

4.2.1. Calculation of Wellbore Pressure Distribution by Different Models. The distribution of wellbore pressure calculated by the six different models for four oil wells is shown in Figure 11. The figure shows that since the measured value has only two pressure points at the wellhead and bottom of the well, the measured pressure distribution in the figure is represented by a straight line, which is different from the actual well distribution. The accuracy of the new model considering the effect of viscosity is higher, as the calculated value is near the measured wellbore pressure distribution curve and the whole wellbore pressure distribution is closer to the measured result. Therefore, the pressure drop model in this paper can be used to predict the pressure distribution of ordinary heavy oil wells.

4.2.2. Calculation Errors of the Different Models. The results of the average relative error and average absolute error rates calculated by the different models are shown in Table 6 . The table shows that the error of the model established in this paper is the smallest, as the average absolute error rate is basically within $15 \%$, and the calculation errors of most existing methods are greater than $20 \%$. Therefore, the prediction results of the new model considering the influence of viscosity and predicting the negative friction pressure drop are better than those of the existing model, and the reliability of the prediction model given in this paper is verified from practical engineering applications in the field.

\section{Conclusions}

To obtain an accurate method for calculating heavy oil-gas two-phase pressure drops in different viscosities, experiments on gas-liquid two-phase flow with different viscosities were carried out. Analysis of the experimental data shows that the total pressure drop increases with increasing liquid viscosity when the superficial gas and liquid flow rates are the same and that the liquid superficial velocity is $0.52 \mathrm{~m} / \mathrm{s}$ and the superficial gas velocity is $12 \mathrm{~m} / \mathrm{s}$ in the vertical and inclined pipes. The friction pressure drop is negative when the superficial gas and liquid velocities are small, as the increased range of the total pressure drop decreases with increasing liquid viscosity. A prediction model of the pressure drop in high-viscosity liquid-gas two-phase flow is established. The new model is verified by experimental data and compared with existing models. The new model has the smallest error, which is basically within $15 \%$. The prediction results of the wellbore pressure distribution of four wells in the BeiA oilfield show that the predicted wellbore pressure distribution of the new model is closer to the measured results, as the error of the new model is the smallest. The reliability of the new model considering the influence of viscosity and predicting the negative friction pressure drop is proven from practical engineering applications in the field.

\section{Data Availability}

The data used to support the findings of this study are available from the corresponding author upon request.

\section{Conflicts of Interest}

The authors declare that they have no conflicts of interest.

\section{Acknowledgments}

The authors gratefully express their thanks for the financial support for this study from the National Major Scientific and Technological Special Project of China (2016ZX05056004-002) and the National Natural Science Foundation of China (61572084).

\section{References}

[1] Z. Liu, R. Liao, W. Luo, Y. Su, and J. X. F. Ribeiro, "A new model for predicting slug flow liquid holdup in vertical pipes with different viscosities," Arabian Journal for Science and Engineering, vol. 45, no. 9, pp. 7741-7750, 2020.

[2] Z. L. Liu, R. Q. Liao, W. Luo, and J. Ribeiro, "A new model for predicting liquid holdup in two-phase flow under high gas and liquid velocities," Scientia Iranica, vol. 26, no. 3, pp. 15291539, 2019.

[3] Z. L. Liu, R. Q. Liao, and W. Luo, "Friction pressure drop model of gas-liquid two-phase flow in an inclined pipe with high gas and liquid velocities," AIP Advances, vol. 9, no. 8, article $085025,2019$.

[4] J. Schmidt, H. Giesbrecht, and C. W. M. van der Geld, "Phase and velocity distributions in vertically upward high-viscosity two-phase flow," International Journal of Multiphase Flow, vol. 34, no. 4, pp. 363-374, 2008.

[5] H. Q. Q. Zhang, D. H. H. Vuong, and C. Sarica, "Modeling high-viscosity oil/water cocurrent flows in horizontal and vertical pipes," SPE Journal, vol. 17, no. 1, pp. 243-250, 2012.

[6] B. C. C. Jeyachandra, B. Gokcal, A. Al-Sarkhi, C. Sarica, and A. K. K. Sharma, "Drift-velocity closure relationships for slug two-phase high-viscosity oil flow in pipes," SPE Journal, vol. 17, no. 2, pp. 593-601, 2012.

[7] S. Farsetti, S. Farisè, and P. Poesio, "Experimental investigation of high viscosity oil-air intermittent flow," Experimental Thermal \& Fluid Science, vol. 57, no. 9, pp. 285-292, 2014.

[8] S. Chung, E. Pereyra, C. Sarica, G. Soto, F. Alruhaimani, and J. Kang, "Effect of high oil viscosity on oil-gas flow behavior in vertical downward pipes," in 10th North American Conference on Multiphase Technology, pp. 259-270, Banff, Canada, June 2016.

[9] F. Al-Ruhaimani, E. Pereyra, and C. Sarica, "Experimental analysis and model evaluation of high-liquid-viscosity twophase upward vertical pipe flow," SPE Journal, vol. 22, no. 3, pp. 712-735, 2016.

[10] D. T. Akhiyarov, H. Q. Zhang, and C. Sarica, "High-viscosity oil-gas flow in vertical pipe," in Offshore Technology Conference, pp. 1-8, Houston, TX, USA, May 2010.

[11] L. Liu, "The phenomenon of negative frictional pressure drop in vertical two-phase flow," International Journal of Heat and Fluid Flow, vol. 45, no. 1, pp. 72-80, 2014. 
[12] A. Al-Sarkhi, E. Pereyra, C. Sarica, and F. Alruhaimani, "Positive frictional pressure gradient in vertical gas-high viscosity oil slug flow," International Journal of Heat and Fluid Flow, vol. 59, pp. 50-61, 2016.

[13] E. Al-Safran, C. Kora, and C. Sarica, "Prediction of slug liquid holdup in high viscosity liquid and gas two-phase flow in horizontal pipes," Journal of Petroleum Science \& Engineering, vol. 133, pp. 566-575, 2015.

[14] H. Q. Zhang, C. Sarica, and E. Pereyra, "Review of highviscosity oil multiphase pipe flow," Energy \& Fuels, vol. 26, no. 7, pp. 3979-3985, 2012.

[15] Y. Taitel and A. E. Dukler, "A model for predicting flow regime transitions in horizontal and near horizontal gas-liquid flow," AIChE Journal, vol. 22, no. 1, pp. 47-55, 1976.

[16] D. Barnea, "A unified model for predicting flow-pattern transitions for the whole range of pipe inclinations," International Journal of Multiphase Flow, vol. 13, no. 1, pp. 1-12, 1987.

[17] H. Mukherjee and J. P. Brill, "Liquid holdup correlations for inclined two-phase flow," Journal of Petroleum Technology, vol. 35, no. 5, pp. 1003-1008, 1983.

[18] I. M. Alves, E. F. Caetano, K. Minami, and O. Shoham, "Modeling annular flow behavior for gas wells," SPE Production Engineering, vol. 6, no. 4, pp. 435-440, 1991.

[19] O. Baker, "Design of pipe lines for simultaneous flow of oil and gas," in Fall Meeting of the Petroleum Branch of AIME, Dallas, TX, USA, October 1953.

[20] K. Aziz and G. W. Govier, "Pressure drop in wells producing oil and gas," Journal of Canadian Petroleum Technology, vol. 11, no. 3, 1972.

[21] A. R. Hasan and C. S. Kabir, "Predicting multiphase flow behavior in a deviated well," SPE Production Engineering, vol. 3, no. 4, pp. 474-482, 1988.

[22] L. Ruiquan, W. Qisheng, and Z. Bainian, “A new method for calculating the pressure gradient of multiphase pipe flow in wellbore," Journal of Jianghan Petroleum Institute, vol. 2, no. 1, pp. 61-65, 1998.

[23] A. S. Kaya, C. Sarica, and J. P. Brill, "Comprehensive mechanistic modeling of two-phase flow in deviated wells," Oil Well, vol. 16, no. 3, pp. 156-165, 1999. 